\title{
Position for Determining Gas Phase Volatile Organic Compound Concentrations in Transuranic Waste Containers
}

M. J. Connolly

S. M. Djordjevic*

K. J. Liekhus

C. A. Loehr*

L. R. Spangler*

Published August 1995

Idaho National Engineering Laboratory

Transuranic Waste Programs

Lockheed Idaho Technologies Company

Idaho Falls, Idaho 83415

*Developed in conjunction with

Benchmark Environment Corp.

Under Subcontract No. C90-132787

Prepared for the

U.S. Department of Energy

Environmental Restoration and Waste Management

Under DOE Idaho Operations Office

Contract DE-AC07-94ID13223 


\section{DISCLAIMER}

This report was prepared as an account of work sponsored by an agency of the United States Government. Neither the United States Government nor any agency thereof, nor any of their employees, make any warranty, express or implied, or assumes any legal liability or responsibility for the accuracy, completeness, or usefulness of any information, apparatus, product, or process disclosed, or represents that its use would not infringe privately owned rights. Reference herein to any specific commercial product, process, or service by trade name, trademark, manufacturer, or otherwise does not necessarily constitute or imply its endorsement, recommendation, or favoring by the United States Government or any agency thereof. The views and opinions of authors expressed herein do not necessarily state or reflect those of the United States Government or any agency thereof. 


\section{DISCLAIMER}

Portions of this document may be illegible in electronic image products. Images are produced from the best available original document. 


\begin{abstract}
In the conditional no-migration determination (NMD) for the test phase of the Waste Isolation Pilot Plant (WIPP), the U.S. Environmental Protection Agency (EPA) imposed certain conditions on the U.S. Department of Energy (DOE) regarding gas phase volatile organic compound (VOC) concentrations in the void space of transuranic (TRU) waste containers. Specifically, the EPA required the DOE to ensure that each waste container has no layer of confinement that contains flammable mixtures of gases or mixtures of gases that could become flammable when mixed with air. The EPA also required that sampling of the headspace of waste containers outside inner layers of confinement be representative of the entire void space of the container. The EPA stated that all layers of confinement in a container would have to be sampled until DOE can demonstrate to the EPA that sampling of all layers is either unnecessary or can be safely reduced.

A test program was conducted at the Idaho National Engineering Laboratory (INEL) to demonstrate that the gas phase VOC concentration in the void space of each layer of confinement in vented drums can be estimated from measured drum headspace using a theoretical transport model and that sampling of each layer of confinement is unnecessary. This report summarizes the studies performed in the INEL test program and extends them for the purpose of developing a methodology for determining gas phase VOC concentrations in both vented and unvented TRU waste containers. The methodology specifies conditions under which waste drum headspace gases can be said to be representative of drum gases as a whole and describes a method for predicting drum concentrations in situations where the headspace concentration is not representative. The methodology addresses the approach for determining the drum VOC gas content for two purposes: operational period drum handling and operational period no-migration calculations.
\end{abstract}





\section{EXECUTIVE SUMMAFIY}

The U.S. Environmental Protection Agency (EPA) placed requirements related to waste container headspace gas sampling on the U.S. Department of Energy (DOE) in the conditional no-migration determination (NMD) for the test phase of the Waste Isolation Pilot Plant (WIPP) (55 FR 47700). One of the conditions of the NMD is that the DOE must ensure that each waste container emplaced underground at the WIPP has no layer of confinement that contains flammable mixtures of gases or mixtures of gases that could become flammable when mixed with air. For the purpose of a no-migration demonstration, DOE was also required to characterize nonflammable volatile hazardous constituents in containers of TRU waste. The EPA required that headspace sampling be representative of the entire void space of the waste container. The EPA stated that all layers of confinement in a container would have to be sampled until the DOE can demonstrate to the EPA, based on data collected, that sampling of all layers is either unnecessary or can be safely reduced.

To address the EPA's conditions and demonstrate that sampling all layers of confinement is unnecessary, a test program was conducted at the Idaho National Engineering Laboratory (INEL) to demonstrate that the VOC concentration in the void space of each layer of confinement in vented drums can be predicted from measured drum headspace data using a steady-state model, which incorporates theoretical diffusion

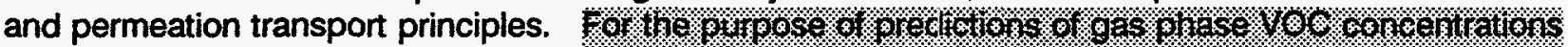

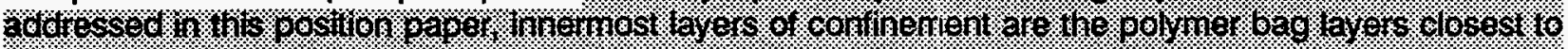

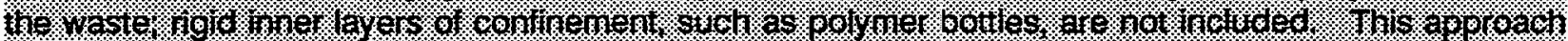

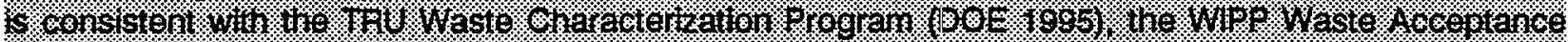

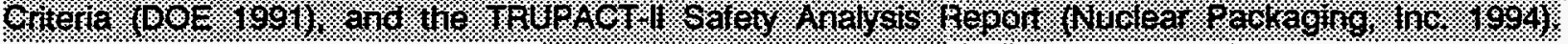

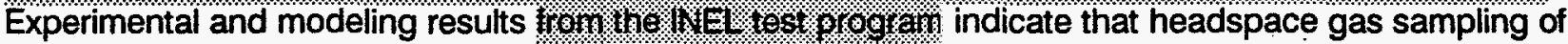
inner layers of confinement is not necessary to characterize VOC concentrations in the void volumes of TRU waste containers and to safely handle and manage TRU waste at the WIPP facility. This position paper presents the proposed approach that will be taken in determining gas phase VOC concentrations in drums for the following two purposes:

1. Operational period drum handling calculations;

2. Operational period no-migration calculations

The approach is based on the results and models of the INEL. test program.

Transient VOC transport models have been used to establish a drum age criterion (DAC) that each TRU waste drum must meet prior to sampling and analysis of the headspace gases. The DAC defines the time required after waste packaging to reach 90-percent of steady-state concentration within all polymer (i.e., plastic) layers of confinement. The DAC must be met prior to sampling headspace gases to help ensure that analysis results are appropriate for their intended use. In computing the DAC, two drum configurations were considered and indicator VOCs were used. The indicator VOCs were selected on the basis of health risks and magnitude of concentration. The DAC is 225 days for drums of Waste Types I and IV and 142 days for drums of Waste Types II and III.

The steady-state and transient modeling is based on fundamental principles and has been verified using simulated waste and waste from the INEL and Rocky Flats Environmental Technology Site (Rocky Flats). The simulated waste characteristics used in verification were similar to waste that is found throughout the DOE complex. Because the packaging configurations and materials used in the DOE complex as a whole are not expected to differ substantially from those usecl at the INEL and Rocky Flats and in model verification, the model is expected to perform similarly for other wastes in the DOE complex. 
The following position is presented:

- If the drum is unvented and the DAC has been met, modeling shows that the headspace gas inside the drum liner is representative of the drum gases and will be used for operational period drum handling and no-migration calculations.

- If the drum is vented and the DAC has been met, the innermost bag gas phase VOC concentration can be predicted from the measured headspace gas concentration and this concentration will be used for operational period drum handling. If the drum is vented and the DAC has been met, the headspace concentration will be used for operational period no-migration calculations.

- $\quad$ For operational period drum handling calculations, the selected concentration values will be summed over flammable VOCs for each drum.

The innermost bag gas phase VOC concentration will be predicted from headspace measurements using VOC-specific factors that approximate the steady-state model developed by the INEL; the factors range from 1.1 to 9.5 for Waste Types I and IV and from 1.7 to 39 for Waste Types II and III. 
TABLE OF CONTENTS

Page

ABSTRACT

ii

EXECUTIVE SUMMARY

iii

LIST OF TABLES

vi

1.0 INTRODUCTION

1-1

2.0 BACKGROUND

2-1

3.0 VOC TRANSPORT STUDIES

3-1

3.1 Transient Modeling for Simulated Vented Drums

3-1

3.2 Steady-State Modeling for Simulated Vented Drums

3-4

3.3 Steady-State Modeling for Actual Vented Drumis

3-6

4.0 DRUM AGE CRITERION FOR HEADSPACE GAS SAMPLING

4-1

5.0 DISCUSSION OF TRANSPORT MODELING

$5-1$

6.0 PROPOSED APPROACH

6-1

6.1 Operational Period Drum Handling

6-1

6.2 Operational Period No-Migration Calculations

6-1

7.0 REFERENCES

\section{LIST OF APPENDICE\$S}

Appendix

Title

A

Drum Age Criterion Model

B

Steady-State VOC Transport Model

C

Estimation of VOC Permeability in Polyethylene and Solubility in Drum Liners

D Drum Age Criterion Models: Modeling Inputs and Assumptions, Results, and Codes

E Selection of Indicator VOCs

F Steady-State Model Inputs 




\section{ACRONYMS AND ABBREVIATIONS}

$\begin{array}{ll}\text { CH } & \text { contact-handled } \\ \text { DAC } & \text { drum age criterion } \\ \text { DOE } & \text { U. S. Department of Energy } \\ \text { EPA } & \text { U. S. Environmental Protection Agency } \\ \text { LEL } & \text { lower explosive limit } \\ \text { LTL } & \text { lower tolerance limit } \\ \text { INEL } & \text { Idaho National Energy Laboratory } \\ \text { MARD } & \text { mean absolute relative deviation } \\ \text { NMD } & \text { no-migration determination } \\ \text { ROcky Flats } & \text { Rocky Flats Environmental Technology Site } \\ \text { TRU } & \text { transuranic } \\ \text { TRUPACT-II } & \text { Transuranic Package Transporter-II } \\ \text { VOC } & \text { volatile organic compound }\end{array}$




\section{POSITION FOR DETERMINING GAS PHASE \\ VOLATILE ORGANIC COMPOUND CCNCENTRATIONS \\ IN TRANSURANIC WASTE COINTAINERS}

\subsection{INTRODUCTION}

Characterization of transuranic (TRU) wastes destined for the Waste Isolation Pilot Plant (WIPP) will include sampling of gases in the headspaces of waste drums for volatile organic compounds (VOCs). The headspace gas VOC concentrations will be used to determine potential flammability of gases and 8.98

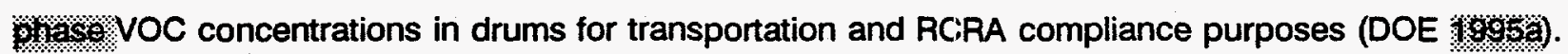
The Environmental Protection Agency (EPA) placed requirements related to waste container headspace gas sampling on the U.S. Department of Energy (DOE) in the conditional no-migration determination (NMD) for the test phase of the WIPP facility (55 FR 47700). DOE plans to submit a no-migration variance petition to EPA for the WIPP facility. As part of this petition, DOE will address questions raised by EPA regarding container headspace VOC representativeness of the entire waste container void space.

One of the conditions of the NMD is that DOE must ensure that each waste container emplaced underground at the WIPP has no layer of confinement that contains flammable mixtures of gases or mixtures of gases that could become flammable when mixed with air. For purposes of a no-migration demonstration, DOE must also characterize the nonflammable volatile hazardous constituents in TRU waste containers. In addition, the EPA required that headspace sampling be representative of the entire void space of the waste container. The EPA stated that all layers of confinement in a container would have to be sampled until DOE can demonstrate to the EPA, based on the data collected, that sampling of all layers is either unnecessary or can be safely reduced. The purpose of this position paper is to propose a methodology to address these conditions and alleviate the requirement of sampling all layers of confinement.

A test program was conducted at the Idaho National Engineering Laboratory (INEL) to demonstrate that the VOC concentration in the void space of each layer of confinement in vented drums can be estimated using measured drum headspace and a model incorporating theoretical diffusion and permeation transport principles and that sampling of each layer of confinement is unnecessary. The model and model validation results provide information that are used to acldress the headspace VOC concentration representativeness issue raised by the EPA for vented containers.

This report presents the methodology for determining gassofosesv VOC concentrations in both vented and unvented drums for existing waste packaging configurations. The methodology specifies conditions 
under which drum headspace gases can be said to be representative of drum gases as a whole and describes a method for predicting drum concentrations in situations where the headspace concentration

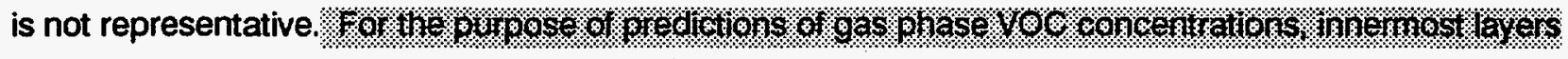

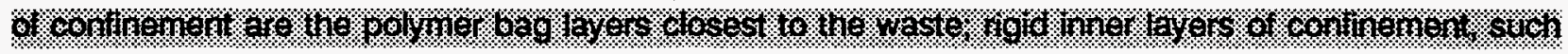

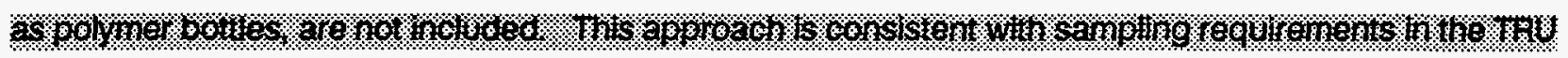

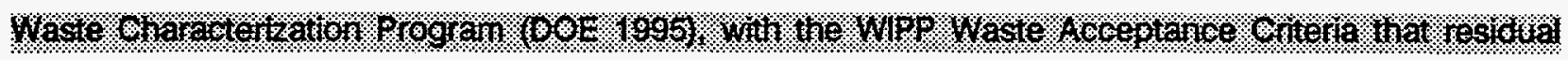

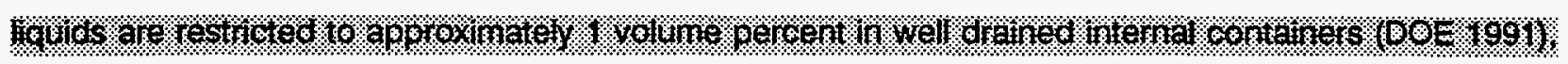

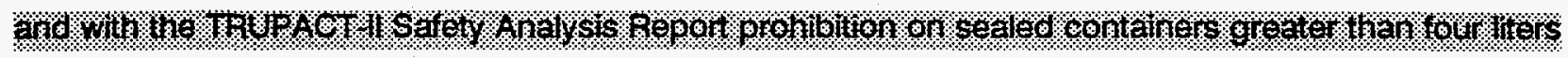

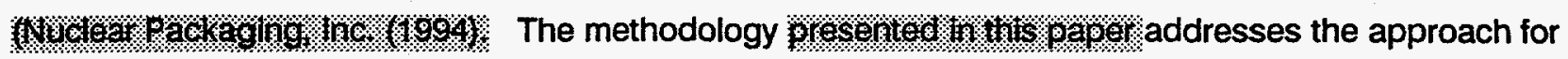
determining the drum VOC gas content for two purposes: operational period drum handling and operational period no-migration calculations. 


\subsection{BACKGROUND}

For purposes of transporting waste in the Transuranic Package Transporter-ll (TRUPACT-II), DOE classified contact-handled $(\mathrm{CH})$ TRU waste materials into four major waste types based on their chemical and physical characteristics, as follows (DOE 1992):

$\begin{array}{lll}\text { I } & - & \text { Solidified aqueous or homogeneous inorganic solids } \\ \text { II } & - & \text { Solid inorganics } \\ \text { III } & - & \text { Solid organics } \\ \text { IV } & - & \text { Solidified organics }\end{array}$

Each $\mathrm{CH}$ TRU waste container is designated by a TRUPACT-II shipping category based on waste type and the packaging (number and type of layers of confinement) of the waste materials within the waste container. The layers of confinement include polymer (i.e., plastic) bags, rigid drum liners and drum filter vents. The polymer bags are sealed by a twist-and-tape or fold-and-tape method. If the bags are sealed by twist-and-tape the resulting closure is referred to as a horsetail. Drums of Waste Type I or Waste Type IV are referred to as sludge waste drums and may contain abscrbed, adsorbed, or solidified inorganic or organic liquids, soils, or solidified particulates and residues. Sludge waste is typically packaged using at most two layered large polymer bags within the rigid drum liner. Drums containing Waste Type II or Waste Type III are referred to as solid waste drums that may contain glass, metal, crucibles, plastics, cellulose, or other solid organics and inorganics. Solid waste drums have up to 6 layers of confinement within the rigid drum liner: a maximum of two layered large polymer bags containing waste wrapped

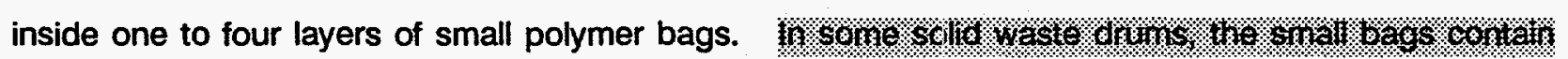

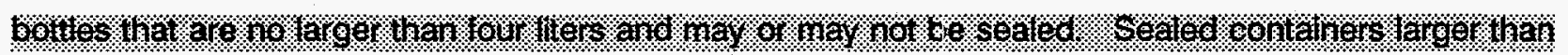

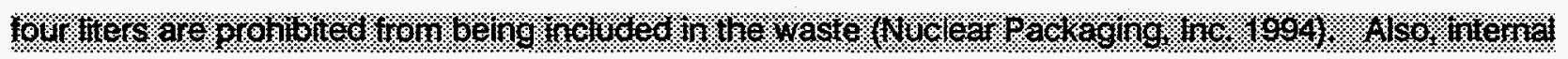

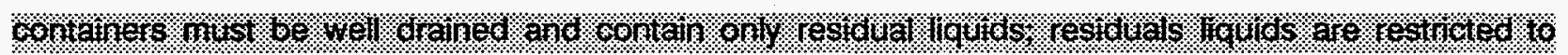

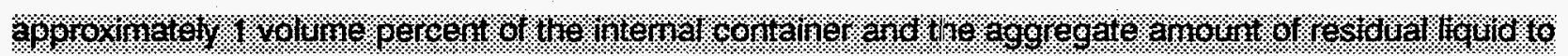

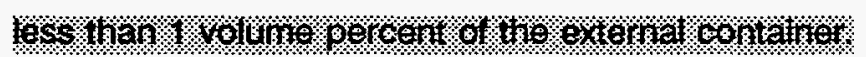

Besides the packaging configuration, the drums can be in three different conditions, depending on whether or not steady-state or equilibrium conditions between layers of confinement have been attained. These three conditions are referred to as drum categories in this report. Each drum category is addressed separately in assessing the representativeness of headspace gas vOC concentrations for drum VOCs as a whole. The three drum categories are:

- Drum Category 1, Existing Vented Drums: The existing vented drums are those that were stored as unvented drums and subsequently vented, the rigid drum liners punctured, and stored again for a period of time. Drums in this category must have been unvented for a sufficient time such that equilibrium concentrations existed within all confinement layers at the time of venting. 
- $\quad$ Drum Category 2, Newly Packaged Vented Drums: The newly packaged vented drums consist of drums and associated rigid drum liners that were vented at the time of packaging. In this category, steady-state concentrations do not exist within all confinement layers at the time of packaging.

- Drum Category 3, Existing Unvented Drums: The existing unvented drums are those drums that have been stored as unvented drums for a period of time. The drums are to be vented (i.e., the drum liners punctured and carbon composite filters installed in the drum lids) and headspace gas samples taken from inside the rigid drum liners at the time of venting. 


\subsection{VOC TRANSPORT STUDIES}

The INEL test program was developed to predict innermost bag gas phase VOC concentrations from the headspace gas VOC concentrations using VOC transport models and data obtained from waste drum sampling. This program consisted of three stages. In the first stage, a model was developed to demonstrate that the transient VOC transport from vented laboratory-scale drums could be estimated based on transport parameters and prior knowledge of the initial gas. Fiass VOC concentration inside the drum. In the second stage, a VOC gas transport model was developed to estimate VOC concentration in the headspace of of the innermost layer of confinement in laboratory-scale vented waste drums containing simulated waste sludge with a high VOC content. In the third stage, the model developed in the second stage was used to estimate gas. prase VOC concentrations in actual waste drums. Measured VOC concentrations were used to evaluate model performance. The development of the mechanistic VOC transport models allows application of the models to VOCs and drum conditions not observed empirically. The VOCs that were tested during model development and evaluation were selected because the compounds represent the range of physical properties (e.g., molecular weight, polarity, vapor pressure, number of carbon atoms, chemical functional groups, permeability) of the 29 VOCs for which gas samples collected from all TRU waste drums destined for the WIPP are analyzed (Table 3-1). The 29 VOCs are those required in the NMD ( 55 FR 47700) that have been determined to be common to all sites (DOE 1995 ). Descriptions of the test program stages and results are summarized in three major reports (Liekhus et al. 1994a; Liekhus et al. 1994b; Liekhus /99\%). The results of the test program described in this section are used to support the position on determining gas phase vOC concentrations in TRU drums.

\subsection{Transient Modeling for Simulated Vented Drums}

In the first stage of the test program, a transient VOC transport model was developed to estimate the Diase VOC concentration within laboratory-scale waste drums as a function of time (Liekhus et al. 1994a). The testing demonstrated that transient gas phase VOC concentrations can be predicted based on theoretical transport mechanisms. Model equations accounted for three primary mechanisms for VOC transport from a void volume. These mechanisms were VOC permeation across a polymer confinement layer, VOC diffusion across an opening in a layer of confinement, and VOC solubility in a polymer confinement layer. The governing equations describing transport of VOCs across the various layers of confinement are provided in Appendix A.

In order to test the transient VOC transport model, experiments were performed to measure VOC concentrations throughout laboratory-scale simulated waste drums. Each waste drum consisted of a sized-down 55-gallon metal drum containing a modified 90-mil high-density rigid polyethylene drum liner. Four small polyethylene bags were sealed inside a large polyethylene bag, supported by a wire cage and 
TABLE 3-1

Volatlle Organic Compounds

Compounds

Acetone

Benzene

Bromoform

n-Butanol

Carbon tetrachloride

Chlorobenzene

Chloroform

Cyclohexane

1,1-Dichloroethane

1,2-Dichloroethane

1,1-Dichloroethylene

cis-1,2-Dichloroethylene

Ethyl benzene

Ethyl ether

Methanol

Methyl ethyl ketone

Methyl isobutyl ketone

Methylene chloride

1,1,2,2-Tetrachloroethane

Tetrachloroethylene

Toluene

1,1,2-Trichloro-1,2,2-trifluoroethane

1,1,1-Trichloroethane

Trichloroethylene

1,2,4-Trimethylbenzene

1,3,5-Trimethylbenzene

$\mathrm{m}$-xylene

o-xylene

p-xylene 
placed inside the punctured drum liner. The small bags were each filled with four liters of a voc-air mixture and the concentrations within each layer of confinement of a waste drum were measured as a function of time. Measurements of the VOC concentrations were taken from six locations inside a simulated waste drum: each small bag headspace, large bag headspace, and drum headspace. Sixteen trials were performed based on a two-level, three-variable experimental design with two replications. Test variables included the initial VOC gas mixtures placed in the small bags, the type of small bag closure, and the presence or absence of a variable external heat source. Two standard gas mixtures (Standard gas mixtures $A$ and B) were used with five VOCs in air comprising each standard mixture. Standard gas mixture A contains methylene chloride, 1,1,2-trichloro-1,2,2-trifluoroethane, carbon tetrachloride, trichloroethylene, and 1,1,1-trichloroethane. Standard gas mixture B contains 1,1,1-trichloroethane, methanol, cyclohexane, toluene and p-xylene.

The single-component pressure change method was used to cletermine VOC solubility in a polyethylene bag. The mixed-component chromatography detection method was used to determine individual VOC permeability in a polyethylene bag, for each VOC in standard gas mixture A. Details of the two experimental methods and an analysis of the experimental results may be found in Liekhus et al. (1994a). Permeability measurements for the VOCs in the standard gas mixture B were not completed due to system limitations in handling high boiling-point (i.e. low vapor pressure) VOCs such as toluene and p-xylene. Permeabilities of VOCs in standard gas mixture B were later measured during the second stage of the test program.

The VOC transport model simulated transient VOC transport for those experiments where the VOC permeability had been measured (Liekhus et al. 1994a). Model input included specifying the total permeable and diffusional surface areas, transport lengths, void volumes, VOC permeabilities and solubilities in polyethylene, transfer coefficients, VOC diffusivities in air and through carbon composite fitters and the initial gas phasse VOC concentrations. Most moclel parameters, such as surface areas and void volumes, were measured or estimated from available process information. Other parameters that were not measured directly were estimated using the VOC transport model and laboratory-scale waste drum data from a single experimental trial. The results of the selected trial were used because the drum temperature was constant and no leaks were identified in the small bags. Model parameters determined using the results of that trial were then used in all subsequent model simulations.

The mean absolute relative deviation (MARD), defining the mean absolute difference between model predictions and experimental values relative to the initial concentration for a given trial, was calculated for small bag, large bag, and drum headspace void volumes. In most trials, the small bag MARD for each high-permeability VOC was less than 2 percent of the initial fess eflase VOC concentration introduced in the small bags. The average MARD value for the low-permeability VOC (1,1,2-trichloro-1,2,2-trifluoroethane) 
was greater than for the high-permeability VOCs as the result of less accurate model estimates. The large bag MARD followed the same trends as observed for the small bags. The MARD for the drum headspace void volume in waste drums maintained at room temperature was less than 2 percent for a majority of the trials. The MARD for the drum headspace void volume in waste drums maintained under a variabletemperature environment was between 2 percent and 4 percent. The increase in the deviation between the model and experimental results in the heated drums was attributed to the failure of the model to account for increased VOC solubility in the polyethylene drum liner at higher temperatures (Liekhus et al. 1994a).

Experimental results demonstrated that VOC transport from waste drums exposed to a variable external heat source was greater than drums maintained at a constant temperature (Liekhus et al. 1994a). The difference was attributed to an increase of VOC solubility in the polyethylene liner at higher temperatures and an increased rate of aspiration due to fluctuating drum temperature. The model does predict lower drum headspace VOC concentrations in a waste drum exposed to thermal cycling instead of being maintained at room temperature but does not account for the temperature dependence of VOC solubility in the polymer drum liner.

The effect of the small bag closure type on VOC transport in the laboratory-scale drum could not be determined from a direct comparison of measured gas. of ase VOC concentration in small bags. Because the model had been demonstrated to accurately follow the small bag gas.phase VOC concentration over the course of the test period, the model was used to estimate the relative importance of VOC transport through a small bag horsetail compared to VOC permeation across the bag wall in the laboratory-scale experiments. For the case of a low-permeability VOC, the rate of VOC transport via permeation was estimated to be over 500 times greater than the VOC transport rate across the horsetail (Liekhus et al. 1994a). Gas transport from polyethylene or polyvinylchloride bags containing 1,1,1-trichloroethane, 1,1,2trichloro-1,2,2-trifluoroethane, or other VOCs with similar permeability across the polymer, are not significantly affected by bag closure types (i.e. horsetail or heat-sealed) (Liekhus 199 ). Thus, permeation is the dominant mechanism of VOC transport across bags and diffusion through the horsetails may be ignored.

\subsection{Steady-State Modeling for Simulated Vented Drums}

In the second stage of the INEL program, a steady-state transport model was developed to predict concentrations in laboratory-scale vented waste drums containing simulated waste sludge based on knowledge of drum headspace VOC concentration and waste drum configuration (Liekhus et al. 1994b). The model consisted of a series of material balance equations describing steady-state VOC transport across each layer of confinement. It was assumed that permeation is the primary transport mechanism across the polymer bags and diffusion across the opening in the punctured (vented) rigid drum liner and 
across the filter vent in the drum lid is the primary transport mechanism. In addition, it was assumed that an equilibrium exists between the vapor phase $\mathrm{VOC}$ concentration and the $\mathrm{VOC}$ in the sludge within the innermost layer of confinement. The governing equations describing transport of VOCs across the various layers of confinement and details of the steady-state VOC transport model are provided in Appendix B.

Two experiments, or trials, were performed to measure the gastofiase vOC concentration in laboratoryscale vented waste drums containing simulated waste sludge (Liekhus et al. 1994b). In Trial 1, a simulated waste sludge containing methylene chloride, 1,1,1-trichloroethane, 1,1,2-trichloro-1,2,2trifluoroethane, carbon tetrachloride, and trichloroethylene was placed inside a large polyethylene bag inside the waste drum. In Trial 2, a simulated waste sludge containing methanol, cyclohexane, 1,1,1trichloroethane, toluene, and p-xylene was placed inside two small polyethylene bags located inside a large polyethylene bag. Permeabilities of four additional VOCs (methanol, cyclohexane, toluene and $p$ xylene) in polyethylene were measured using the mixed-component chromatographic detection method. Details of the experimental effort including the experimental design, procedures employed, and quality control procedures are provided in Liekhus et al. (1994b).

Experimental results were expressed as a ratio between drum headspace VOC concentration and the $\mathrm{ges}$ Ofase VOC concentration inside the innermost polyethylene bag. The concentration ratio was calculated to minimize daily fluctuations that affected all measurements on a given day. The daily concentration ratio also demonstrated when transport rates were nearly equivalent. An average concentration ratio was calculated for all waste drums in a given trial. Most concentration ratios were compound-dependent and approached a constant value indicative of nearly equal transport rates (quasi steady-state conditions) from the innermost layer of confinement and the drum headspace. During Trial 1 , the time required for the concentration ratio to reach a constant value varied between 10 to 50 days, depending on the VOC. During Trial 2, the concentration ratio for toluene and p-xylene did not reach a constant value after 86 days (the length of the trial). The time necessary to reach a near-constant value is a function of the drum filter diffusion characteristic, total number of layers of confinement, and the VOC vapor pressure. Model results for all VOCs that did reach a constant value were within an approximate 95 percent confidence interval for the mean ratio of headspace-to-bag concentration (Liekhus et al. 1994b).

Model equations were used to determine the effect of model parameters on the estimated concentration difference across a transport boundary, such as the rigid drum liner or polymer bag. The gas. Pf ssse VOC concentration difference across the rigid drum liner will decrease with a larger cross-sectional area of the opening in the rigid liner lid or a smaller VOC diffusion characteristic across the drum filter vent. The concentration difference across the polymer bag will decrease with a larger permeable surface area or a smaller polymer bag thickness. These variables are a function of the waste packaging configuration. In addition, a smaller VOC diffusion characteristic across the drum filter vent or a larger VOC permeability 
within the polymer bag will also decrease the concentration difference. Vapor permeabilities increase with increasing vapor concentration. All VOC permeabilities used in model calculations were measured at vapor concentrations less than those measured during the laboratory-scale waste drum experiments. Depending on the waste drum configuration, the use of a larger permeability value could reduce the estimated concentration difference across a polymer bag. Using a VOC permeability that was measured across an identical or similar polymer at a lower vapor concentration than exists under actual conditions will result in a conservative estimate of the concentration difference across the bag (Liekhus et al. 1994b).

\subsection{Steady-State Modeling for Actual Vented Drums}

In the third stage of the INEL experimental program, the model developed in the second stage was used to estimate gos plasese VOC concentrations in actual waste drums from INEL and the Rocky Flats Environmental Technology Site (Rocky Flats). The effectiveness of the model in estimating gas orfase VOC concentration was examined for vented waste drums containing different waste types and packaging configurations. The model results demonstrated that maximum gass 8 fasse VOC concentrations within actual waste drums can be estimated from drum headspace gas sampling data. Gas samples were collected from 22 sludge waste drums (Waste Types I and IV) containing solidified sludge within a maximum of 2 layers of polymer bags. Gas samples were collected and analyzed at Rocky Flats. Gas sampling and waste characterization of 42 waste drums containing solid waste (Waste Types II and III) were performed at the Argonne National Laboratory - West. The solid waste drums sampled had a maximum of 4 or 5 layers of polymer bags. Details of the gas sampling and analysis, equipment used, procedures employed and quality control procedures are provided in Liekhus 1095 ).

The diffusion characteristics of hydrogen and 9 VOCs across different drum filter vents were measured in experiments performed at the INEL (Liekhus 1995 ). Based on the results of the experiments, a predictive method can successfully estimate VOC diffusion characteristics across a filter vent based on the measured hydrogen diffusion characteristic and the predicted ratio of VOC-air diffusivity to hydrogenair diffusivity. Thus for those VOCs without experimental data the VOC diffusion characteristic may be estimated as:

$$
D_{\text {VOC }}^{*}=\frac{D_{\text {VOC-air }}}{D_{H_{2} \text {-air }}} D_{H_{2}}^{*}
$$

where,

$\begin{array}{lll}D_{\text {VOC }}^{*} & = & \text { VOC diffusion characteristic across the drum filter vent } \\ D_{H 2}^{*} & = & \text { Hydrogen diffusion characteristic across the drum filter vent } \\ D_{\text {VOC-air }} & = & \text { VOC diffusivity in air }\end{array}$




$$
\mathrm{D}_{\mathrm{H2} \text {-air }} \quad \text { Hydrogen diffusivity in air }
$$

The ratio of the VOC to hydrogen diffusivity in air can be estimated using the Slattery equation as (Liekhus \%):

$$
\frac{D_{\text {VOC-alr }}}{D_{H_{2} \text {-arr }}}=\left[\frac{p_{G \text { VOC }}}{p_{c, H_{2}}}\right]^{1 / 3}\left[\frac{T_{G \text { VOC }}}{T_{G, H_{2}}}\right]^{-1 / 2}\left[\frac{-\frac{1}{M_{\text {alr }}}+\frac{1}{M_{V O C}}}{\frac{1}{M_{\text {air }}}+\frac{1}{M_{H_{2}}}}\right]^{1 / 2}
$$

where,

$\begin{array}{lll}\mathrm{P}_{\mathrm{c}, \mathrm{VOC}} & = & \text { Critical pressure of the VOC (atm) } \\ \mathrm{P}_{\mathrm{c}, \mathrm{H} 2} & = & \text { Critical pressure of hydrogen (atm) } \\ T_{\mathrm{c}, \mathrm{VOC}} & = & \text { Critical temperature of the vOC }(\mathrm{K}) \\ T_{c, \mathrm{H} 2} & = & \text { Critical temperature of hydrogen }(\mathrm{K}) \\ M_{\text {air }} & = & \text { Molecular weight of air }(\mathrm{g} / \mathrm{mol}) \\ \mathrm{M}_{\mathrm{VOC}} & = & \text { Molecular weight of voC }(\mathrm{g} / \mathrm{mol}) \\ M_{\mathrm{H} 2} & = & \text { Molecular weight of hydrogen }(\mathrm{g} / \mathrm{mol})\end{array}$

When measured values of VOC permeability in polyethylene were not available, they were calculated as the product of the estimated values of VOC diffusivity in polyethylene, $D_{V O C-P E}$, and VOC solubility in polyethylene, $\mathbf{S}$. The method used to estimate VOC permeability is presented in Appendix $C$.

In order to quantify the accuracy of the transport model results, the logarithm of the ratio of the predicted VOC concentration in the headspace of the innermost layer of confinement, $Y_{\text {mod, }}$, the maximum VOC concentration measured in all bag headspaces, $Y_{\max }$, was calculated as

$$
\Psi=\log _{10}\left[\frac{Y_{\bmod }}{Y_{\max }}\right]
$$

In the case where the model estimate and measured jas. pllase VOC concentrations are identical, $\psi$ equals zero. The VOC transport model is considered to be accurate if the 95-percent confidence limits on the mean $\psi$ bound the case of $\psi=0$. Otherwise, the model is said to have a positive or negative bias. This means that model estimates of the maximum os os asse VOC concentration in a specific population of waste drums are consistently greater or less than the maximum fieasueded concenilation. The steady-state transport model described in Appendix B was used to estimate the concentration of 17 VOCs 
and the total VOC concentration in characterized by the maximum number of layers of polymer bags.

Model calculations were performed for the VOCs in two sets. The first set consisted of 8 VOCs in which VOC-specific parameters (i.e., VOC permeability across the polyethylene bags and the drum filter vent VOC diffusion characteristic), were measured. Model calculations were performed for other VOCs using estimated values for VOC-specific parameters discussed earlier. The VOCs for which model calculations were performed are listed in Table 3-2.

Model accuracy (degree of bias) was determined for 13 of the 17 VOCs in which model calculations were performed. Four VOCs were omitted because of lack of a sufficient number of detectable concentrations. Table 3-3 summarizes model accuracy results. Transport model predictions were unbiased or positively biased (i.e., over estimated) for the maximum measured jessofosese concentrations of 12 VOCs within

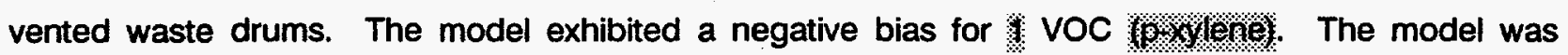

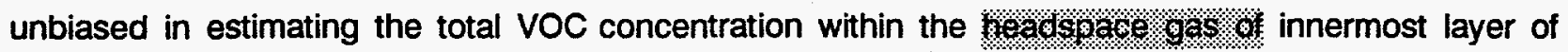
confinement for waste drums containing a maximum of four layers of polymer bags that were all sampled within one day and exhibiting detectable concentrations in inner bags. The model exhibited a positive bias in estimating the total VOC concentration within the .heacspace gas a off the innermost layer of confinement of waste drums containing a maximum of two or five layers of polymer bags.

Model precision was characterized for 13 VOCs and three drum configurations by the lower 90/90 tolerance limit (LTL) for $\psi$. One can be 90-percent confident that for at least 90-percent of waste drums, the calculated value of $\psi$ will exceed the LTL for $\psi$. In other words, the 90/90 LTL is a statistical expression for a lower bound that $\psi$ is likely to exceed.

The 90/90 LTL on $\$$ may be expressed as percent of maximum measured inner bag eas. phasse concentration. Table 3-4 summarizes the 90/90 LTLs on $\psi$ in this way. The table gives the percentage of maximum measured inner bag gas. phase concentration that corresponds to the 90/90 LTL for each VOC and for total VOC Gassolase concentration for 3 packaging configurations. The VOC transport model predicts an innermost bag gas.phase vOC concentration that, with 90-percent confidence, will not be less than 50 percent of the maximum measured. cooncentratlon in at least 90 percent of the waste drums for 9 VOCs and two of the waste drum configurations. The VOC transport model predicts that the

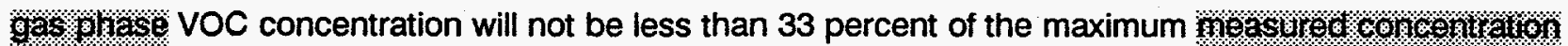
in at least 90 percent of the waste drums for 2 VOCs and waste drums with a maximum of four layers of polymer bags. For carbon tetrachloride and methanol, model estimates will not be less than 20 percent of the maximum measured gas phase VOC concentration in at least 90 percent of the waste drums. 
TABLE 3-2

VOCs for Which Model Calculations Were Performed

VOC

Acetone ${ }^{a}$

Benzene

Carbon tetrachloride $e^{a, b}$

Chloroform $^{a}$

1,1-Dichloroethane ${ }^{a}$

1,1-Dichloroethylene ${ }^{a}$

Ethyl benzene

Methanol $^{a, b}$

Methylene chloride ${ }^{a, b}$

1,1,2,2-Tetrachloroethane

Tetrachloroethylene ${ }^{a}$

Toluene $e^{a, b}$

1,1,1-Trichloroethane ${ }^{a, b}$

Trichloroethylene ${ }^{a, b}$

1,1,2-Trichloro-1,2,2-trifluoroethane $e^{a, b}$

o-xylene

p-xylene $e^{a, b}$

a VOCs for which model accuracy and precision were evaluated.

bOCs for which measured characteristics were available. 
TABLE 3-3

\section{Percent Confidence Limits on Mean $\downarrow$ and Model Blas}

\begin{tabular}{|c|c|c|c|}
\hline voc/Drum Configuration & $\begin{array}{l}\text { Lower } 95 \% \\
\text { Confidence Limit }\end{array}$ & $\begin{array}{c}\text { Upper } 95 \% \\
\text { Confidence Limit }\end{array}$ & Model Bias \\
\hline Two bag layers $^{b}$ & 0045 & 0.111 & positive \\
\hline Four bag layers ${ }^{b}$ & -0.125 & 0.097 & none \\
\hline Five bag layers $^{b}$ & OBO & $6 \% 6$ & positive \\
\hline Acetone & 0.69 & 038 & Postine \\
\hline Carbon tetrachloride & -0.182 & 0.154 & none \\
\hline Chloroform & $\%$ & $\%$ & none \\
\hline 1,1-Dichloroethane & 0.058 & $0 \% 62$ & none \\
\hline 1,1-Dichloroethylene & $0 \% 8$ & 026 & positive \\
\hline Methanol & -0.241 & 0.363 & none \\
\hline Methylene chloride & -0.022 & 0.108 & none \\
\hline Tetrachloroethylene & 010 & 0.05 & none \\
\hline 1,1,1-Trichloroethane & 0.077 & 0.159 & positive \\
\hline Trichloroethylene & -0.101 & 0.013 & none \\
\hline 1,1,2-Trichloro-1,2,2-tritluoroethane & 0.295 & 0.375 & positive \\
\hline Toluene & -0.090 & 0.003 & none \\
\hline p-xylene & -0.178 & -0.006 & negative \\
\hline
\end{tabular}

${ }^{a}$ Data from Liekhus (1995).

bTotal measured gas phase VOC concentration. 


\section{TABLE 3-4}

90/90 LTLs on $\downarrow$ Expressed as Percent of Maximum Measured Inner Bag Gas Phase Concentration ${ }^{\mathrm{a}}$

VOC/Drum Configuration

Percent

Two bag layers ${ }^{b}$

Four bag layers $^{b}$

Five bag layers ${ }^{b}$

Acetone

Carbon tetrachloride

Chloroform

1,1-Dichloroethane

1,1-Dichloroethylene

Methanol

Methylene chloride 61

Tetrachloroethylene

Toluene

1,1,1-Trichloroethane

Trichloroethylene

1,1,2-Trichloro-1,2,2-trifluoroethane

p-xylene

Data from Liekhus (195).

${ }^{b}$ Total measured ogs of as as VOC concentration. 


\subsection{DRUM AGE CRITERION FOR HEADSFACE GAS SAMPLING}

There is a certain age criterion that must be met by a drum of TRU waste in order for headspace gas samples to be either representative of gases in the drum or appropriate to use in predicting innermost bag VOC gas phase concentration. The drum age criterion (DAC) defines the age of a drum necessary to reach 90-percent of steady-state concentration within all of the bags and the rigid drum liner. The DAC establishes the time after waste packaging necessary to wait prior to drum headspace sampling to help ensure that the headspace sample analyses are suitable for their intended use.

DACs for two packaging configurations have been determined using transient VOC transport models and indicator VOCs selected on the basis of health risks and magnitıde of concentration. The DACs are given in Table 4-1. For drums of Waste Types I and IV, the DAC is 22.5 days. For drums of Waste Types II and III, the DAC is 142 days. The governing equations for the models used are given in Appendix $A$. Methods for estimating permeability and solubility in polyethylene are described in Appendix C. Modeling inputs and assumptions, results, and codes are provided in Appendix $D$. The selection of the indicator VOCs is described in Appendix E. The methodology for determining the DACs is summarized below.

Indicator VOCs were selected by using two separate screening techniques and having the screened VOCs comprise the set of indicator VOCs. The screening teclnniques are consistent with the purposes for determining gas phase VOC concentrations in drums; one of the screening techniques focused on flammability issues related to operational period drum handling and the second focused on human health risk from inhalation for the operational period. To screen for operational period drum handling, the magnitude of VOC concentration in headspace gas samples from 465 INEL and Rocky Flats drums was examined.

TABLE 4-1

Drum Age Criteria

\begin{tabular}{cc}
\hline $\begin{array}{c}\text { Waste Types I and IV } \\
\text { (days) }\end{array}$ & Waste Types II and III \\
(days) & 142 \\
\hline
\end{tabular}


VOCs were screened and included as indicator VOCs if the VOC is flammable and the mean detected concentration exceeded $146 \mathrm{ppmv}$. The value $146 \mathrm{ppmv}$ was determined based on a lower explosive limit (LEL) of 9,000 ppmv for a gaseous mixture, the 19 flammable VOCs that may be present in the mixture (DOE 1995 ), and the potential innermost bag gas phase VOC concentrations. The screening limit is based on the requirement that to be nonflammable, the following must hold for a mixture with 19 flammable VOCs in the innermost bag of a drum:

$$
19 \times I B<9,000
$$

where IB is the innermost bag gas phase VOC concentration. The maximum ratio between the predicted inner bag concentration and observed headspace concentration for all VOCs and drums modeled in Liekhus (1995) is 3.24. Therefore,

$$
H S \times 3.24=I B
$$

where HS is the headspace VOC concentration. Then,

$$
H S<146
$$

must hold true and VOCs with headspace concentrations greater than $146 \mathrm{ppmv}$ were included in the indicator VOC set.

The screening for operational period human health risk was conducted using the scoring technique outlined in EPA (1989) on the hazardous VOCs being examined for the WIPP facility and is consistent with the draft no-migration variance petition (DOE 19953). The VOCs that represented approximately 99percent of the risk and hazard calculated using EPA-approved toxicity factors for inhalation and the average concentrations observed in the headspace analyses of INEL and Rocky Flat drums, weighted by Waste Matrix Code Group (DOE 19950) to reflect DOE complex inventory, were the VOCs included with the indicator VOCs from the drum handling screening. Of necessity, VOCs for which no toxicity factors were available were omitted from the screening process; these VOCs were omitted from the set of indicator VOCs also.

The screening resulted in 11 distinct indicator VOCs. For drum handling, n-butanol, methyl ethyl ketone, methyl isobutyl ketone, and methanol were screened for inclusion in the indicator set. For operational period human health risk, 1,1-dichloroethylene, carbon tetrachloride, chlorobenzene, chloroform, 
methylene chloride, methyl ethyl ketone, 1,1,2,2-tetrachloroethane, trichloroethylene, and toluene were screened and included as indicator VOCs.

A computer program was used to calculate the required drum age or vent time ${ }^{1}$ for each indicator VOC for three drum categories and two drum packaging configurations. The program implements the governing equations from Appendix $A$ using the code and inputs given in Appendix D. The initial conditions used in the computations depend on the drum category (i.e. existing vented drums, newly packaged drums, and existing unvented drums). The required drum age or vent time is the time required for the system to reach 90 -percent of its steady-state value.

Two packaging drum configurations were considered in determining the DACs from the calculated drum ages and vent times. For drums containing sludges (Waste Types I and IV), there are two large bags within the rigid drum liner providing two inner layers of confinement. For solid waste (Waste Types II and III), it is conservatively assumed that five layers are within the rigid drum liner. ${ }^{2}$ The drum filter type is assumed to be NFT-020 for both packaging configurations; this assumption is considered conservative since NFT-020 filters are the most restrictive regarding the release of compounds of filter types being used in the DOE complex (Liekhus 1994). The longer of the follovring, for each configuration and over all indicator VOCs, are taken as the DACs:

- Calculated vent time for newly packaged vented drums and

- The sum of calculated vent time for existing vented drums and calculated drum age for existing unvented drums

The DACs that result are given in Table 4-1. Potential future packaging configurations (e.g., those using filtered bags) were not considered and will require additional analyses to determine the appropriate DAC.

The initial conditions applied for solving the governing equations are different for each drum category and are summarized as follows:

- $\quad$ For Drum Category 1, Existing Vented Drums, initially the concentration in all bag headspaces and within the rigid drum liner headspace are the same. The initial concentration in the drum headspace is zero. A constant zero concentration outside the drum is assumed. The initial condition is based on the assumption of an equilibrium condition within the drum prior to venting. Therefore, the drum must be old enough to have reached equilibrium conditions throughout the drum prior to the time it was vented isee Drum Category 3: Existing Unvented

\footnotetext{
${ }^{1}$ For Category 3 drums, the required drum age was calculated. For Drum Categories 1 and 2, the required vent times were calculated.

${ }^{2} \mathrm{~A}$ maximum of six layers is identified in TRUCON codes but it has been observed that the majority of the drums have less than five layers.
} 
Drums). In other words, if the drums had been sampled at the time of venting, this category would not be necessary and the drum would fall into Drum Category 3.

- For Drum Category 2, Newly Packaged Vented Drums, the initial concentration inside the drum is zero except for the innermost bag whose concentration is a constant. A constant zero concentration outside the drum is assumed.

- For Drum Category 3, Existing Unvented Drums, the initial concentration inside the drum is zero, except for the innermost bag, whose concentration is a constant. The equations describing the change in headspace concentrations within the large bag and drum liner are then solved to determine the time when the concentrations in all layers of polymer confinements have equilibrated. 


\subsection{DISCUSSION OF TRANSPORT MODELING}

The INEL test program and its associated transport modeling (Section 3.0) demonstrates that VOC transport can be modeled based on mathematical simulation of diffusion and permeation processes. This demonstration took place in three stages: transient VOI transport from vented laboratory-scale drums, steady-state VOC transport in laboratory-scale vented waste drums containing simulated waste sludge and the application of the steady-state model to actual vaste drums. Based on comparing model results to actual waste drum concentrations, the steady-state VOC transport model demonstrated that innermost bag gas phase VOC concentrations can be predictecl from headspace gas concentration data. Because these predictions can be made, sampling and analysis of inner layers of confinement will not be necessary.

The predictions can be made using prediction factors that conservatively approximate the steady-state model predictions. The prediction factors are derived by solving the steady-state model in terms of the ratio between the innermost layer gas phase VOC concentration and the headspace gas VOC concentration. The prediction factors have been compisted for 29 VOCs for the two packaging configurations used for the DACs and using inputs listed in Appendix $F$. The inputs are consistent with those used in the steady-state modeling described in Section :3.3 where model predictions of innermost layer gas phase VOC concentrations compared favorably to maximum gas phase concentrations observed in waste drums. Use of the prediction factors will be conservative for cases where the actual package has fewer layers than that assumed for the prediction factor. The prediction factors are also based on conservative assumptions of filter diffusivities. Permeabilities used in computing the prediction factors are the same as those used in computing DACs. The prediction factors are given in Table 5-1 and range from 1.1 to 9.5 for Waste Types I and IV and from 1.7 to 39 for Waste Types II and III. To predict the innermost bag gas phase VOC concentration, the headspace gas VOC concentration and associated prediction factor should be multiplied.

The steady-state VOC transport model and the prediction factors are valid when the DAC has been met. The DAC establishes the time after waste packaging necessany to wait prior to drum headspace gas sampling to be able to accurately predict the innermost layer gas phase VOC concentration within a drum. The innermost layer gas phase VOC concentration prediction vill be the maximum predicted value. The DAC also establishes the waiting time that will ensure that; the transport rates between layers of confinement are equal and headspace concentrations can be used in calculations for emissions through the drum filter. 
TABLE 5-1

Factors for Prediction of Innermost Bag Gas Phase VOC Concentration from Headspace Gas VOC Concentration

\begin{tabular}{|c|c|c|}
\hline & Waste Types I and IV & Waste Types II and III \\
\hline Acetone & 1.9 & 5.1 \\
\hline Benzene & 1.5 & 3.4 \\
\hline Bromoform & 1.1 & 1.7 \\
\hline n-Butanol & 1.5 & 3.2 \\
\hline Carbon tetrachloride & 1.6 & 3.9 \\
\hline Chlorobenzene & 1.3 & 2.3 \\
\hline Chloroform & 1.5 & 3.5 \\
\hline Cyclohexane & 9.5 & 39 \\
\hline 1,1-Dichloroethane & 1.7 & 4.1 \\
\hline 1,2-Dichloroethane & 1.4 & 2.7 \\
\hline 1,1-Dichloroethylene & 2.1 & 6.1 \\
\hline cis-1,2-Dichloroethylene & 1.5 & 3.3 \\
\hline Ethylbenzene & 1.4 & 3.2 \\
\hline Ethyl ether & 3.8 & 13 \\
\hline Methanol & 2.3 & 6.8 \\
\hline Methyl ethyl ketone & 1.8 & 4.5 \\
\hline Methyl isobutyl ketone & 1.8 & 4.8 \\
\hline Methylene chloride & 1.6 & 3.7 \\
\hline 1,1,2,2-Tetrachloroethane & 1.2 & 1.8 \\
\hline Tetrachloroethylene & 1.3 & 2.3 \\
\hline Toluene & 1.2 & 2.3 \\
\hline 1,1,1-Trichloroethane & 1.8 & 4.8 \\
\hline Trichloroethylene & 1.3 & 2.4 \\
\hline 1,1,2-Trichloro-1,2,2-trifluoroethane & 3.6 & 13 \\
\hline 1,2,4-Trimethylbenzene & 1.4 & 2.8 \\
\hline 1,3,5-Trimethylbenzene & 1.4 & 3.0 \\
\hline m-Xylene & 1.4 & 3.1 \\
\hline o-Xylene & 1.4 & 2.7 \\
\hline p-Xylene & 1.2 & 2.1 \\
\hline
\end{tabular}


If the drum is unvented (Drum Category 3) and the DAC has been met, modeling shows that the headspace gas within the rigid liner is representative of the drum gases within all layers of polymer confinement, because equilibrium has been reached. If the drum is vented (Drum Categories 1 and 2) and the DAC has been met, the innermost gas concentration can be predicted from the headspace gas concentration using the prediction factors in Table 5-1. The predicted innermost bag concentration is concluded to conservatively represent the maximum concentration within a drum. In addition, if the DAC has been met, the headspace concentration for Drum Categories 1 and 2 can be said to represent headspace concentrations that control the rate of emissions through the drum filter over time.

The steady-state and transient modeling is based on fundamerital principles and has been verified using simulated waste and waste from the INEL and Rocky Flats. The simulated waste characteristics were similar to waste that is found throughout the DOE complex. Modeling inputs are based on empirical data and empirical correlations, but are VOC-specific rather than waste-specific. Because modeling is not waste-specific, it is applicable to waste in the DOE complex as a whole. Sampling and analysis of the void space in inner layers of confinement of selected drums will be performed during waste characterization (DOE 1995a). The analysis results may be used to corroborate the modeling studies on INEL and Rocky Flats wastes; however, because the packaging configurations and materials used in the DOE complex as a whole are not expected to differ substantially from those used at the INEL and Rocky Flats, the model is expected to perform similarly for other wastes in the DOE complex. The screening for indicator VOCs for determining the DAC used headspace gas VDC concentration data from sampled INEL and Rocky Flats waste weighted by Waste Matrix Code Group (DOE 199\%) to reflect inventory in the DOE complex. Because of this, and because Rocky Flats waste is believed to have the highest concentrations of VOCs in the complex, the screening is assumed to be appropriate for the DOE complex. 


\subsection{PROPOSED APPROACH}

The proposed approach provides prescriptions for determining drum gas phase VOC concentrations for operational period drum handling and operational period no-migration calculations for each of the three drum categories. The prescriptions are based on the DAC being met prior to headspace sampling and involve methodologies outlined below. Either headspace gas measurements or predictions of innermost bag concentrations, as appropriate, will be used.

\subsection{Operational Period Drum Handling}

Gas phase VOC concentrations in drums will be determined for the purpose of assessing flammability. The maximum gas phase VOC concentration is the concentration of interest for this assessment. The approach is to use predicted concentrations for the maximum in cases where the headspace concentration is not representative of the maximum. The basis steps to the approach are as follows:

1. Determine the drum packaging configuration.

2. Establish and meet the DAC.

3. Sample and analyze headspace gas.

4. Determine Drum Category. Determine drum concentrations as follows:

a. For existing vented drums (Drum Category 1), determine the predicted value using the factors in Table 5-1. The predicted value will be used for the drum concentration.

b. For newly packaged vented drums (Drum Category 2), the predicted value will be used as for existing vented drums (see a.).

c. For existing unvented drums (Drum Category 3), headspace concentrations within the rigid drum liner will be used, because the DAC ensures representativeness.

The selected flammable VOCs concentration values will be summed for each drum.

\subsection{Operational Period No-Migration Calculations}

Gas phase VOC concentrations in drums will be determined for the purpose of calculating VOC emissions through drum filters. Because steady-state conditions are required, the VOC emission rate from a vented drum is a function of the drum headspace VOC concentration and the VOC diffusion characteristic across the drum filter. Cas.pyase VOC concentrations in inner layers of confinement are not used, and thus are not selected for the drum concentration; rather, the approach is to use headspace concentrations. The basic steps to the approach are as follows: 
1. Determine the drum packaging configuration.

2. Establish and meet the DAC.

3. Sample and analyze headspace gas.

4. Determine Drum Category. Determine drum concentrations as follows:

a. For existing vented drums (Drum Category 1), the headspace concentration will be used.

b. For newly packaged vented drums (Drum Category 2), the headspace concentration will be used as for existing vented drums.

c. For existing unvented drums (Drum Category 3), headspace concentrations within the rigid drum liner will be used. 


\subsection{REFERENCES}

55 FR 47700. 1990. "Conditional No-Migration Determination for the Department of Energy Waste Isolation Pilot Plant (WIPP)." Federal Register 55 (November 14): pp. 47700-47721.

Brodkey, R. S. and H. C. Hershey. 1988. Transport Phenomenon: A Unified Approach, McGraw-Hill Book Company, New York, New York.

DOE. 1992. TRUPACT-I/ Content Codes (TRUCON). Rev. 6, DOE:MIPP 89-004, Waste isolation Pilot Plant, U.S. Department of Energy, September.

DOE. 1995a. Transuranic Waste Characterization Quality Assurance Program Plan. Revision 0 , CAO-94-1010, Carlsbad, New Mexico, Waste Isolation Pilot Plant, U.S. Department of Energy, July 8.

DOE. 1995b. Draft Waste Isolation Pilot Plant No-Migration Variance Petition, Phase I Submittal. DOE/CAD-DRAFT-2043, Carlsbad New Mexico, Waste Isolation Pilot Plant, U.S. Department of Energy, May, in preparation.

DOE 1995c. Waste Isolation Pilot Plant Transuranic Waste Baseline Inventory Report. Revision 1 , CAO-94-1005, U.S. Department of Energy, February.

EPA. 1989. Risk Assessment Guidance for Superfund, Volume 1, Human Health Evaluation Manual (Part A). EPA/540/1-89/002, Washington, D.C., U.S. Environmental Protection Agency.

Liekhus, K. J. 1994. Transport Characteristics Across Drum Filter Vents and Polymer Bags. EGG-WM-11454, EG\&G Idaho, Idaho Falls, Idaho.

Liekhus, K. J. 3995 . Characterization of Void Volume VOC Concentration in Vented TRU Waste Drums Final Report. Reysion. I, INEL-94/0252, Lockheed Idaho Technologies Company, Idaho Falls, Idaho.

Liekhus, K. J., G. L Gresham, E. S. Peterson, C. Rae, N. J. Hotz, and M. J. Connolly. 1994a. Modeling Unsteady-State VOC Transport in Simulated Waste Drums. EGG-WM-10823, EG\&G Idaho, Idaho Falls, Idaho.

Liekhus, K. J., G. L. Gresham, C. Rae, and M. J. Connolly. 1994b. VOC Transport in Vented Drums Containing Simulated Waste Sludge. EGG-WM-11205, EG\&G Idaho, Idaho Falls, Idaho.

Michaels, A. S. and H. J. Bixler. 1961. "Flow of Gases Through Polyethylene," Journal of Polymer Science, Vol. 50, pp 413-439.

Michaels, A. S. and H. J. Bixler. 1961. "Solubility of Gases in Polyethylene," Journal of Polymer Science, Vol. 50, pp 393-412.

Reid, R. C., J. M. Prausnitz, and B. E. Poling. 1987. The Properties of Gases and Liquids. Fourth edition, McGraw-Hill Book Company, New York, New York. 
APPENDIX A

Drum Age Criterion Mołtel

A-1 


\section{APPENDIX A}

\section{Drum Age Criterion Model}

A VOC transport model has been developed to estimate the transient VOC gas-phase concentration throughout a waste drum. The model consists of a series of material balance equations describing transient VOC transport between each void volume.

\section{Model Equations}

Gas concentration is calculated, assuming ideal gas law, to equal

$$
c=\frac{P}{R T}
$$

where

$$
\begin{aligned}
& \mathrm{C}=\text { gas concentration, } \mathrm{mol} \mathrm{cm} \\
& \mathrm{P}=\text { system pressure, atm } \\
& \mathrm{R}=\text { gas constant }=82.06 \mathrm{~cm}^{3} \text { atm mol} \mathrm{K}^{-1} \mathrm{~K}^{-1} \\
& T=\text { gas temperature, } \mathrm{K}
\end{aligned}
$$

It is assumed that inside a waste drum is a rigid polymer drum liner that contains one or more large polymer bags. Inside the innermost large bag may be smaller polymer bags that contain waste. The innermost void volume containing the waste is considered the first void volume. Subsequent void volumes are numbered accordingly. It is assumed that the primary means of VOC transport out of the small and large polymer bags is by permeation. The rate of VOC permeation is calculated as

$$
Q_{P}=\frac{\phi \rho A_{P} P}{x_{P}} y_{P}
$$

where

$Q_{p}=$ rate of VOC permeation across the polymer bag, mol s

$\phi \quad=4.46 \times 10^{-5} \mathrm{~mol} \mathrm{~cm}^{-3}$, gas concentration at standard temperature, pressure

$\rho=$ VOC permeability coefficient, $\mathrm{cm}^{3}$ (STP) $\mathrm{cm}^{-2} \mathrm{~s}^{-1}(\mathrm{~cm} \mathrm{Hg})^{-1}$

$A_{P}=$ permeable surface area of polymer bag, $\mathrm{cm}^{2}$

$P \quad=$ gas pressure, $\mathrm{cm} \mathrm{Hg}$

$x_{p}=$ polymer bag wall thickness, $\mathrm{cm}$

$y_{p}=$ VOC mole fraction difference across polymer bag boundary. 
The rate of VOC diffusion in air across an opening in the drum liner lid is defined by

$$
Q_{D}=\frac{C D A_{D}}{x_{D}} y_{D}
$$

where

$Q_{D}=$ rate of VOC diffusion across drum liner lid, $\mathrm{mol} \mathrm{s}^{-1}$

$D=$ VOC diffusivity in air, $\mathrm{cm}^{2} \mathrm{~s}^{-1}$

$A_{D}=$ cross-sectional area of opening, $\mathrm{cm}^{2}$

$x_{D}=$ diffusional path length across drum liner lid, crn

$y_{D}=$ VOC mole fraction difference across opening.

Soluble VOCs will accumulate within a polymer until an equilitrium concentration is reached. The rate of accumulation is estimated to be

$$
Q_{s}=\eta \phi V_{p} P\left[s_{\infty}-s\right]
$$

where

$Q_{S}=$ rate of VOC accumulation in drum liner, $\mathrm{mol} \mathrm{s}^{-1}$

$\eta=$ transfer coefficient, $\mathrm{sec}^{-1}$

$v_{p}=$ polymer volume of drum liner, $\mathrm{cm}^{3}$ polymer.

$s_{\infty}=$ VOC equilibrium solubility in drum liner polymer, $\left[\mathrm{cm}^{3}\right.$ (STP) VOC] $\left(\mathrm{cm}^{-3}\right.$ polymer) $(\mathrm{cm} \mathrm{Hg})^{-1}$

$s=$ average $\mathrm{VOC}$ solubility in drum liner polymer, $\left[\mathrm{cm}^{3}\right.$ (STP) VOC] $\left(\mathrm{cm}^{-3}\right.$ polymer) $(\mathrm{cm} \mathrm{Hg})^{-1}$.

The VOC equilibrium solubility in the polymer is estimated as

$$
s_{\infty}=\frac{y_{v}}{H^{*}}
$$

where $y_{v}$ is the volume-average VOC mole fraction in the gas surrounding the polymer and $\mathrm{H}^{\star}$ is the VOC Henry's constant in the drum liner with units of $\mathrm{cm}^{-3}$ (STP) $\left(\mathrm{cm}^{3}\right.$ polymer) $(\mathrm{cm} \mathrm{Hg})$.

The rate of VOC diffusion across a drum filter vent is defined as

$$
Q_{D F}=D^{*} y_{D *}
$$


where

$Q_{D F}=$ rate of VOC diffusion across drum filter vent, $\mathrm{mol} \mathrm{s}^{-1}$

$D^{*}=$ VOC-filter diffusion characteristic, $\mathrm{mol} \mathrm{s}^{-1}$

$y_{D^{*}}=$ VOC mole fraction difference across drum filter vent.

The rate of change of the VOC concentration in each layer of confinement can be defined in terms of the rate of VOC transport from layer. Four different cases representing different waste drum configurations are considered. The subscripts SB, LB, DL, and DH refer to small bag, large bag, drum liner, and drum headspace, respectively.

CASE 1: Small and large bags in vented drum and drum liner

$$
\begin{gathered}
\frac{d c_{S B}}{d t}=0 \\
\frac{d c_{L B}}{d t}=\frac{Q_{P, S B}-Q_{P, L B}}{V_{L B}} \\
\frac{d c_{D L}}{d t}=\frac{Q_{P, L B}-Q_{D}-f_{D L} Q_{S}}{V_{D L}} \\
\frac{d c_{D H}}{d t}=\frac{Q_{D}-Q_{D F}-\left(1-f_{D L}\right) Q_{S}}{V_{D H}}
\end{gathered}
$$

where $V$ is the void volume within the layer of confinement and $f_{D L}$ is the fraction of the total quantity of $V O C$ in the void volume surrounding the drum liner that is contained within the drum liner void volume

$$
f_{D L}=\frac{y_{D L} V_{D L}}{y_{D H} V_{D H}+y_{D L} V_{D L}}
$$

where $y$ is the VOC mole fraction within a given void volume 
CASE 2: Small and large bags in unvented drum

$$
\begin{gathered}
\frac{d c_{S B}}{d t}=0 \\
\frac{d c_{L B}}{d t}=\frac{Q_{P, S B}-Q_{P, L B}}{V_{L B}} \\
\frac{d c_{D L}}{d t}=\frac{Q_{P, L B}-Q_{D}-Q_{S}}{V_{D L}}
\end{gathered}
$$

CASE 3: Large bag only in vented drum and drum liner

$$
\begin{gathered}
\frac{d c_{L B}}{d t}=0 \\
\frac{d c_{D L}}{d t}=\frac{Q_{P, L}-Q_{D}-f_{D L} Q_{S}}{V_{D L}} \\
\frac{d c_{D H}}{d t}=\frac{Q_{D}-Q_{D F}-\left(1-f_{D U}\right) Q_{S}}{V_{D H}}
\end{gathered}
$$

CASE 4: Large bag only in unvented drum

$$
\begin{gathered}
\frac{d c_{L B}}{d t}=0 \\
\frac{d c_{D L}}{d t}=\frac{Q_{P_{, L B}}-Q_{D}-Q_{S}}{V_{D L}}
\end{gathered}
$$




\section{Model Assumptions}

Assumptions made in developing these model equations are listed below.

1. All gases are ideal.

2. Constant temperature and pressure within the waste drum.

3. The VOC concentration within the innermost layer of confinement is constant.

4. VOC concentration within a void volume is uniform at all times.

5. Multiple layers of small or large bags are treated as a single small or large with a total thickness equal to the sum of the thickness of the individual bags.

6. Permeation is considered to be the only significant transport mechanism for VOC out of void volume contained within polymer bag.

7. Diffusion is considered to be the only significant transport mechanism for VOC out of void volume contained within drum liner and drum headspace.

8. Drum filter vent is characterized by its hydrogen diffusion characteristic.

9. The dissolved VOC concentration in the drum liner is uniform at all times.

10. VOC concentration outside the drum filter vent is zero. 


\section{APPENDIX B}

Steady-State VOC Transport Model 


\section{APPENDIX B}

\section{Steady-State VOC Transport Model}

A steady-state transport model was developed to estimate the VOC concentration in void volumes within a vented drum containing waste contaminated with or containing VOCs. Model parameters are defined from knowledge of the waste drum configuration. A waste drum consists of a vented drum with a punctured rigid drum liner that contains the waste inside one or two large polymer bags. The waste may have been placed directly in the innermost large bag or wrapped in one or more layers of smaller polymer bags, which were then placed inside the innermost large polymer bag. The opening in the drum liner lid allows gas and vapor transport between the drum liner and drum headspace. The waste drum configuration includes the type of filter vent in the drum lid, the dimensions of the opening in the drum liner lid, and the thickness and surface area of polymer bags surrounding the waste. The model, consisting of a series of material balance equations describing steady-state VOC transport from each distinct void volume in the drum, is presented below.

A number of assumptions were made to minimize model complexity. Some assumptions were based on an understanding of the thermodynamic and kinetic nature of VOC transport in the waste drum. Other assumptions were based on knowledge of the drum packaging system. In cases where knowledge was lacking, conservative assumptions that would result in higher model estimates of VOC concentrations were made. Major model assumptions are as follows:

- Ideal gas behavior.

- An equilibrium exists between the VOC-contaminated waste and the vapor phase in the innermost layer of confinement.

- In waste drums containing solid waste, all VOC-contaminated waste is contained inside one waste package.

- The VOC transport rates across all layers of confinement are equal and at steady state.

- The primary mechanisms for VOC transport are permeation across the polymer bags and diffusion across the drum liner and drum filter vent.

- A layer of confinement defined by multiple layers of polymer bags is considered a single polymer bag with a bag thickness equal to the sum of the bag thicknesses of the individual bags.

- The VOC concentration throughout each void volume is uniform and is zero outside the waste drum.

- All VOC properties and other model parameters remain constant.

The primary mechanisms for steady-state gas transport across a polymer boundary are permeation across 
the polymer and diffusion across an opening in a layer of confinement. The steady-state gas transport via permeation across a polymer film is defined as

$$
r=\left[\frac{\phi \rho A_{p} P}{x_{p}}\right] c \Delta y_{p}=K_{p} \Delta y_{p}
$$

where,

$$
\begin{array}{ll}
r & =\text { gas transport rate, } \mathrm{mol} \mathrm{s}^{-1} \\
\phi & =76 \mathrm{~T} /(273.15 \mathrm{P}) \\
T & =\text { gas temperature, } \mathrm{K} \\
P & =\text { gas pressure, } \mathrm{cm} \mathrm{Hg} \\
\rho & =\text { gas permeability coefficient, } \mathrm{cm}^{3}(\mathrm{STP}) \mathrm{cm}^{-1}(\mathrm{~cm} \mathrm{Hg})^{-1} \mathrm{~s}^{-1} \\
A_{p} & =\text { polymer surface area across which gas permeates, } \mathrm{cm}^{2} \\
x_{p} & =\text { polymer boundary thickness, } \mathrm{cm} \\
c & =\text { total gas concentration }=\mathrm{P}(\mathrm{RT})^{-1}, \text { mol } \mathrm{cm}^{-3} \\
R & =6236.6 \mathrm{~cm}^{3} \text { (cm Hg) mol } \mathrm{K}^{-1} \\
\Delta y_{p} & =\text { gas mole fraction difference across polymer } \\
K_{p} & =\text { gas permeation characteristic, } 4.46 \times 10^{-5} \mathrm{~A}_{\mathrm{p}} \mathrm{P} \mathrm{x}_{\mathrm{p}}^{-1}, \mathrm{~mol} \mathrm{~s}^{-1}
\end{array}
$$

The steady-state gas transport across an opening in a layer cof confinement via gas diffusion is defined as

$$
r=\left[\frac{D A_{d}}{x_{d}}\right] c \Delta y_{p}=K_{d} \Delta y_{p}
$$

where,

$$
\begin{array}{ll}
D & =\text { gas diffusivity in air, } \mathrm{cm}^{2} \mathrm{~s}^{-1} \\
A_{d} & =\text { cross-sectional area of opening across polymer boundary, } \mathrm{cm}^{2} \\
x_{d} & =\text { diffusional length across opening, } \mathrm{cm} \\
K_{d} & =\text { gas diffusion characteristic, } D A_{d} P\left(R T x_{d}\right)^{-1}, \mathrm{~mol} \mathrm{~s}^{-1} .
\end{array}
$$

\section{Sludge Waste Drums}

The large polymer bag immediately surrounding the sludge waste is the innermost layer of confinement and the headspace within the innermost layer of confinement is referred to as the first void volume. The rigid drum liner headspace not included in the large bags and the drum headspace outside the rigid drum liner are the second and third void volumes, respectively. The VOC transport rate from the innermost layer of confinement, $r$, is defined as follows (where $y_{i}$ is the VOC mole fraction in the $i^{\text {th }}$ void volume): 


$$
r=K_{p}\left(y_{1}-y_{2}\right)
$$

The VOC transport rate from the rigid drum liner is defined as

$$
r=K_{d}\left(y_{2}-y_{3}\right)
$$

The VOC transport rate from the drum headspace across the filter vent is defined as

$$
r=D_{v o c}^{*}\left(v_{3}-y_{\infty}\right)
$$

where,

$$
\begin{aligned}
& D^{*}{ }_{V O C}=\text { drum filter vent } \text { VOC diffusion characteristic, } \mathrm{mol} \mathrm{s}^{-1} \\
& \mathrm{y}_{\infty}=\text { VOC mole fraction outside waste drum }
\end{aligned}
$$

The values of $K_{p}$ and $K_{d}$ are calculated based on drum packaging knowledge. The VOC mole fraction in the drum headspace, $y_{3}$, is determined from analysis of gas samples collected below the filter vent. Equation (B-5) is used to define the steady-state VOC transport rate in the waste drum. The VOC mole fractions in the other void volumes are calculated using Equations (B-3) and (B-4).

$$
\begin{aligned}
& y_{1}=y_{2}+\frac{r}{K_{p}} \\
& y_{2}=y_{3}+\frac{r}{K_{d}}
\end{aligned}
$$

Combining Equations (B-5) through (B-7), the VOC mole fraction within the innermost layer of confinement can be defined directly in terms of the measured $\mathrm{VOC}$ mole fraction in the drum headspace

$$
y_{1}=y_{3}+D_{V O C}^{*} y_{3}\left[\frac{1}{K_{p}}+\frac{1}{K_{d}}\right] .
$$

Multiplying both sides of Equation (B-8) by a constant, the VOC concentration within the innermost layer of confinement can be defined in terms of the drum headspace VOC concentration where $Y_{i}$ is the VOC concentration within the $i^{\text {th }}$ layer of confinement in parts per million (ppm). 


$$
Y_{1}=Y_{3}+D_{v O C}^{*} Y_{3}\left[\frac{1}{K_{p}}+\frac{1}{K_{d}}\right]
$$

\section{Solid Waste Drums}

Most solid waste drums contain waste packaged in one or more layers of small polymer bags. These smaller bags are located inside a large polymer bag. The polymer bag immediately surrounding the waste is the innermost layer of confinement and the headspace inside this layer of confinement is referred to as the first void volume. Large bag, drum liner, and drum headspaces are referred to as the second, third, and fourth void volumes, respectively. The VOC transport rate from the innermost layer of confinement of the $i_{\text {th }}$ waste package wrapped in one or more polymer bags is defined by the equation

$$
r_{i}=K_{p, 1, l}\left(y_{1, i}-y_{2}\right)
$$

where

$$
\begin{aligned}
K_{p, 1, i}= & \text { VOC permeation characteristic of first layer of confinement surrounding the } i^{\text {th }} \text { waste } \\
& \text { package, mol s } \\
y_{1, i} & =\text { VOC mole fraction in headspace of } i^{\text {th }} \text { waste package. }
\end{aligned}
$$

The total VOC transport rate exiting the waste packages and entering the large bag headspace is equal to the sum of individual $V O C$ transport rates from each waste package

$$
r=\sum_{i=1}^{N} r_{i}
$$

where $\mathrm{N}$ is the total number of small bags inside the drum. The VOC transport rate across the large polymer bags containing the waste packages is defined as

$$
r=K_{p, 2}\left(y_{2}-y_{3}\right)
$$

The VOC transport rate across the drum liner is defined as

$$
r=K_{d}\left(y_{3}-y_{4}\right)
$$

The VOC transport rate from the drum headspace across the filter vent is defined as Equation (B-14) is used to define the steady-state vOC transport rate in the drum. The vOC concentration in the drum liner headspace is calculated usingl Equation (B-13) 


$$
\begin{gathered}
r=D_{v o c}^{*}\left(y_{4}-y_{d}\right) \\
y_{3}=y_{4}+\frac{r}{K_{d}}
\end{gathered}
$$

The VOC mole fraction in the large bag headspace is calculated using Equation (B-12)

$$
y_{2}=y_{3}+\frac{r}{K_{p, 2}}
$$

Assuming that the VOC permeability characteristics of all waste packages are identical and that the VOC transport rates from all waste packages are identical, then the VOC mole fraction within the innermost layer of confinement of each waste package is the same and is calculated using Equations (B-10) and (B-11)

$$
y_{1}=y_{2}+\frac{r}{N K_{p, 1}}
$$

The maximum model estimate of the VOC mole fraction in the innermost layer of confinement results if all VOC-contaminated waste is assumed to exist in one bag or $N=1$. Using this assumption and combining Equations (B-14) through (B-17), the VOC concentration within the innermost layer of confinement can be defined in terms of the measured VOC concentration in the drum headspace in an analogous form of Equation (B-9)

$$
Y_{1}=Y_{4}+D_{v O C}^{*} Y_{4}\left[\frac{1}{K_{p, 1}}+\frac{1}{K_{p, 2}}+\frac{1}{K_{d}}\right] .
$$




\section{APPENDIX C}

Estimation of VOC Permeability in Polyethylene and Solubility in Drum Liners 


\section{APPENDIX C}

\section{Estimation of VOC Permeability In Polyethylene and Solubility in Drum Liners}

This appendix documents a methodology for estimating VOC permeabilities in polyethylene based on taking the product of estimated values of VOC diffusivity in polyethylene and estimating values of VOC solubility in polyethylene. If the solubility of a gas in polyethylene is proportional to pressure (Henry's law is applicable) and the gas diffusion constant is independent of pressure, then the gas permeability in polyethylene is defined as

$$
p=D_{v-p} S
$$

where

$$
\begin{array}{ll}
\rho & =\text { VOC permeability in polyethylene, } \mathrm{cm}^{3}(\mathrm{STP}) \mathrm{cm}^{-1} \mathrm{~s}^{-1} \mathrm{~atm}^{-1} \\
D_{\mathrm{v}-\mathrm{p}} & =\text { VOC diffusivity in polyethylene, } \mathrm{cm}^{2} \mathrm{~s}^{-1} \\
\mathrm{~S} & =\text { VOC solubility coefficient in polyethylene, } \mathrm{cm}^{3} \text { (STP) } \mathrm{cm}^{-3} \mathrm{~atm}^{-1}
\end{array}
$$

The VOC permeability in polyethylene can be estimated using known or estimated values for $D_{v-p}$ and $S$. Solubility coefficients were correlated with the Lennard-Jones force constants for the solubilized permeating vapor (Michaels and Bixler 1961a). The VOC solubility coefficient is estimated to be

$$
S=\alpha S_{0}
$$

where,

$$
\begin{array}{ll}
\alpha & =\text { volume fraction of amorphous polymer. } \\
S_{0} & =\text { solubility coefficient in completely amorphous polyethylene } \mathrm{cm}^{3} \text { (STP) } \mathrm{cm}^{-3} \text { atm. }
\end{array}
$$

The value of $\alpha$ may range from 0 to 1.0. An average value of $\alpha=0.5$ should be used in the calculations in the absence of data. The value of $S_{0}$ is estimated as:

$$
S_{0}=\theta^{0.022 \epsilon 1 k-5.07}
$$

where $\epsilon / \mathrm{k}$ is the force constant in the Lennard-Jones (6-12) potential field equation (K).

Diffusion coefficients were estimated based on a correlation with the molecular diameter of the permeating molecule (Michaels and Bixler 1961b). The diffusion coefficient of a permeant in polyethylene is estimated by the equation 


$$
D_{v-p}=\frac{D_{0}}{\tau \beta}
$$

where,

$$
\begin{array}{ll}
D_{0} & =\text { diffusion coefficient in completely amorphous polyethylene }\left(\mathrm{cm}^{2} / \mathrm{s}\right) \\
\tau & =\text { geometric impedance factor } \\
\beta & =\text { chain immobilization factor }
\end{array}
$$

The geometric impedance factor accounts for the reduction in the diffusion coefficient due to the necessity of molecules to bypass crystallites and move through amorphous regions of nonuniform cross-sectional area. The chain immobilization factor takes into account the reduction in amorphous chain segment mobility due to the proximity of crystallites. A correlation to estimate $D_{0}$ at $25^{\circ} \mathrm{C}$ is

$$
\ln \left(\frac{D_{0}}{d^{2}}\right)=3.66-1.32\left[d-0.5 \phi^{0.5}\right]
$$

where $d$ is the gas molecule diameter in $\AA$ and the quantity $0.5 \phi^{0.5}$ is the mean unoccupied distance between two chain segments in the amorphous polymer and is assumed to equal $0.9 \AA$ in all calculations. The gas molecular diameter is estimated from kinetic theory using experimentally determined viscosities or suitable approximations. The term $D_{0} / d^{2}$ is expressed in $10^{9} \sec ^{-1}$.

A correlation for $\beta$ at $25^{\circ} \mathrm{C}$ is

$$
\beta=\theta^{r\left[d-0.5 \phi^{0.52}\right.}
$$

where $\gamma$ is a constant and is characteristic of the polymer and the volume fraction of crystallinity.

A correlation for $\tau$ is

$$
\tau=\alpha^{-n}
$$

where $\mathrm{n}$ is a constant. For linear polyethylenes prepared from Ziegler catalysts and branched, high pressure polyethylenes, $n=1.88$. For linear polyethylenes prepared from Phillips catalysts and hydrogenated polybutadiene, $n=1.25$.

Values of $\mathrm{d}$ and $\epsilon / \kappa$ may be obtained from the following correlations for non-polar molecules (Brodkey and Hershey 1988): 


$$
d=(2.3551-0.087 \omega)\left(\frac{T_{c}}{P_{c}}\right)^{1 / 3}
$$

and

$$
\epsilon / k=(0.7915+0.1693 \omega) T_{c}
$$

where,

$$
\begin{array}{ll}
\mathrm{P}_{\mathrm{c}} & =\text { critical pressure }(\mathrm{atm}) \\
\mathrm{T}_{\mathrm{c}} & =\text { critical temperature }(\mathrm{K}) \\
{ }_{\omega} & =\text { acentric factor }
\end{array}
$$

For polar molecules, a modified Lennard-Jones relation, such as the Stockmayer potential, is often used to estimate values of $d$ and $\epsilon / \kappa$ (Reid et al. 1987). Specifically, Brokaw (Brodkey and Hershey 1988) has suggested the following relations:

$$
d=\left(\frac{1.585 V_{b}}{1+1.3 \delta^{2}}\right)^{1 / 3}
$$

and

$$
\epsilon / k=1.18\left(1+1.3 \delta^{2}\right) T_{b}
$$

where,

$$
\begin{array}{ll}
\mathrm{V}_{\mathrm{b}} & =\text { liquid molar volume at the normal boiling point }\left(\mathrm{cm}^{3} / \mathrm{mol}\right) \\
\mathrm{T}_{\mathrm{b}} & =\text { normal boiling point at } 1 \mathrm{~atm}(\mathrm{~K}) \\
\delta & =\text { dimensionless dipole moment }
\end{array}
$$

The dimensionless dipole moment is calculated as:

$$
\delta=\frac{1.94 \times 10^{3} \mu_{p}^{2}}{V_{b} T_{b}}
$$

where,

$$
\mu_{\mathrm{p}} \quad=\text { dipole moment (debyes) }
$$

Measured VOC permeabilities across polyethylene (Liekhus and Peterson 1995) listed in Table C-1 should be used to define several equation parameters. A value of $\gamma$ should be determined that minimizes the 
error between estimated and experimentally determined permeability values. Equations C-2 and C-3 should be used to estimate solubilities of VOCs in the rigid drum liner. Measured VOC equilibrium concentration in the rigid drum liner (Liekhus and Peterson 19:95) listed in Table C-1 should be used to define the $\alpha$ parameter in Equation $\mathrm{C}-2$.

\section{References}

Brodkey, R. S. and H. C. Hershey. 1988. Transport Phenomenon: A Unified Approach, McGraw-Hill Book Company, New York, New York.

Liekhus, K. J. and E. S. Peterson. 1995. Measurement of VOC Permeability of Polymer Bags and VOC Solubility in Polyethylene Drum Liner. INEL-95/0164, L.ockheed Idaho Technologies Company, Idaho Falls, Idaho.

Michaels, A. S. and H. J. Bixler. 1961a. "Solubility of Gases in Folyethylene," Journal of Polymer Science, Vol. 50, pp 393-412.

Michaels, A. S. and H. J. Bixler. 1961b. "Flow of Gases Through Polyethylene," Journal of Polymer Science, Vol. 50, pp 413-439.

Reid, R. C., J. M. Prausnitz, and B. E. Poling. 1987. The Properties of Gases and Liquids, Fourth edition, McGraw-Hill Book Company, New York, New York. 


\section{Table C-1}

Measured VOC Permeability Across Polyethylene Bag and VOC Equilibrium Concentration in the Rigid Drum Liner

\begin{tabular}{lcc}
\hline VOC & $\rho_{\text {meas }}(\mathrm{Ba})^{\mathrm{a}}$ & $\left.\mathrm{X}_{\text {meas }}\left[\mathrm{cm}^{3}(\mathrm{STP}) / \mathrm{cm}^{3}\right)\right]$ \\
\hline Methylene Chloride & $260 \pm 26$ & 7.321 \\
Carbon Tetrachloride & $190 \pm 36$ & 5.288 \\
1,1,1-Trichloroethane & $140 \pm 12$ & 3.235 \\
Trichloroethylene & $580 \pm 28$ & 11.186 \\
Methanol & $135 \pm 35$ & 4.471 \\
Cyclohexane & $12 \pm 1.7$ & 9.209 \\
Toluene & $670 \pm 120$ & 3.219 \\
p-xylene & $810 \pm 48$ & 6.503 \\
1,1,2-Trichloro-1,2,2-trifluoroethane & $38 \pm 4.9$ & 1.357 \\
\hline
\end{tabular}

$a_{\mathrm{Ba}}=10^{-10} \mathrm{~cm}^{3}(\mathrm{STP}) \mathrm{cm}^{-1} \mathrm{~s}^{-1}(\mathrm{~cm} \mathrm{Hg})^{-1}$. 


\section{APPENDIX D}

Drum Age Criterion Models: Modeling Inputs and Assumptions, Results, and Codes 


\section{APPENDIX D}

\section{Drum Age Criterion Models: Modeling Inputs and Assumptions, Results, and Codes}

The drum vent times or drum ages were calculated for 29 individual VOCs in newly packaged vented drums, existing unvented drums, and existing vented drums. Vent times were calculated for vented drums and drum ages were calculated for unvented drums. Each waste drum contains a rigid polyethylene drum liner itself lined with two polyethylene bags. Waste may be placed directly inside the innermost bag or wrapped in additional polymer bags before being placed in the drum. For each vented or unvented case, drum vent times or ages were calculated for drums that contained two layers of polymer bags or five layers of polymer bags. Drums with only two layers of polymer bags were assumed to contain waste sludge. Drums with five layers of polymer bags were assumed to contain organic and inorganic solid waste.

Equations describing unsteady-state VOC transport in vented waste drums (Liekhus et al. 1994a) serve as the basis for calculating drum vent times in all drums. The equations describe VOC permeation across a polymer bag, diffusion across an opening in a layer of confinement, and VOC solubility in the polyethylene drum liner. A computer program using these equations to describe VOC transport in a vented waste drum was written. The accuracy of the program was tested by comparing model estimates of the ratio between the VOC concentration in the drum headspace and the innermost layer of confinement to experimental ratio values in laboratory-scale vented waste drums containing simulated waste sludge (Liekhus et al. 1994b). Two different experiments were performed. In the first experiment, a small quantity of simulated waste sludge was placed in an open vial inside one polyethylene bag. The waste sludge contained carbon tetrachloride, 1,1,1-trichloroethane, trichloroethylene, methylene chloride, and 1,1,2-trichloro-1,2,2-trifluoroethane. In the second experiment, two open vials containing simulated waste sludge were placed in separate small polyethylene bags suspended inside the larger bag. This simulant contained cyclohexane, 1,1,1-trichloroethane, toluene, methanol, and p-xylene.

The values of most model parameters had been determined in these earlier experiments. ${ }^{1,10}$ In both experiments the void volume in the drum headspace was $16,000 \mathrm{~cm}^{3}$. The lab-scale drum liner had a diameter of $55.8 \mathrm{~cm}$, a height of $31.8 \mathrm{~cm}$, and a nominal wall thickness of $0.23 \mathrm{~cm}$. The cross-sectional area of the opening in the drum liner lid is $0.71 \mathrm{~cm}^{2}$. A diffusion length across the opening of $1.2 \mathrm{~cm}$ was estimated from unsteady-state experimental results (Liekhus et al. 1994a). The void volume of a completely empty drum liner is $62,000 \mathrm{~cm}^{3}$. The exposed drum liner surface area was estimated to be $8,000 \mathrm{~cm}^{2}$. The base of the drum liner was excluded since it is not readily exposed to the gas phase. All bags used were polyethylene with a nominal thickness of $0.01 \mathrm{~cm}$. The larger polymer bag was supported on a cage with a diameter of $47.3 \mathrm{~cm}$ and a height of $20.6 \mathrm{~cm}$. The sealed bag was assumed to have a diameter and height that was $5.1 \mathrm{~cm}$ and $2.5 \mathrm{~cm}$, respectively, greater than that of the cage. 
The maximum void volume in the cage-supported bag is approximately $49,800 \mathrm{~cm}^{3}$. Therefore, the drum liner headspace void volume is approximately $12,200 \mathrm{~cm}^{3}$. The total permeable area for the cagesupported bag is estimated to be $6,000 \mathrm{~cm}^{2}$. The linear dimensions of the smaller heat-sealed bags were $30.5 \mathrm{~cm}$ by $45.7 \mathrm{~cm}$. The maximum permeable surface area for each bag is $2,800 \mathrm{~cm}^{2}$. The total small bag permeable surface area is $5,600 \mathrm{~cm}^{2}$. Air was introduced into the bag to prevent the bag walls from collapsing around the vial. In this case, the void volume of each bag was estimated to be $1,000 \mathrm{~cm}^{3}$. Thus, in the second experiment, the void volume within the large bag was approximately $47,800 \mathrm{~cm}^{3}$. The hydrogen diffusion characteristic of NFT-020 filter is $42 \times 10^{-7} \mathrm{~mol} \mathrm{~s}^{-1}$. Average measured VOC permeabilities in polyethylene bags were used (Liekhus and Peterson 1995). Experiments were performed to define the VOC Henry's constant in the drum liner and mass transfer coefficients (Liekhus and Peterson 1995).

A comparison of model and experimental concentration ratios in the lab scale waste drum showed good agreement except in the cases of toluene and cyclohexane. Initial model estimate of the time required for toluene to reach near steady-state conditions (90 percent of steady-state ratio) was much less (37 days) than was observed ( $>86$ days). In the case of cyclohexane, model estimate (161 days) was much greater than actual case (15 to 20 days). Since the model estimate of the toluene steady-state concentration ratio was similar to the actual ratio observed, it was concluded that toluene permeability used in model calculations was correct. The discrepancy between model and actual concentration ratio was attributed to Henry's constant used in original calculations. In the case of cyclohexane, the estimated model ratio of 0.60 is much less than the experimental value of 0.67 . This may be due to the use of a permeability in model calculations that is less than in the actual system. In addition, an assumption of no concentration gradient within the drum liner may not be appropriate given the low permeability of cyclohexane in polyethylene.

Since the exact variation of VOC equilibrium concentration in the drum liner with VOC mole fraction in the gas phase could not be defined without additional data, the Henry's constants for toluene and cyclohexane used in model calculations were adjusted until time to reach near steady-state conditions more closely approximated the experimental results. This method of estimating the Henry's constant was used only in the case of toluene and cyclohexane. These constants were used in subsequent model calculations in actual waste drums. A comparison of the final model estimates of the VOC concentration ratios in laboratory-scale waste drum to experimental results are shown in Figures D-1 and D-2. It was assumed that the VOC concentration within the innermost layer remained constant. This was not always the case observed in some laboratory-scale waste drums and was attributed to insufficient quantity of waste sludge during the experiment. However, the good agreement between the estimated and actual ratios over the entire duration of the laboratory-scale experimerits demonstrates that complete knowledge 


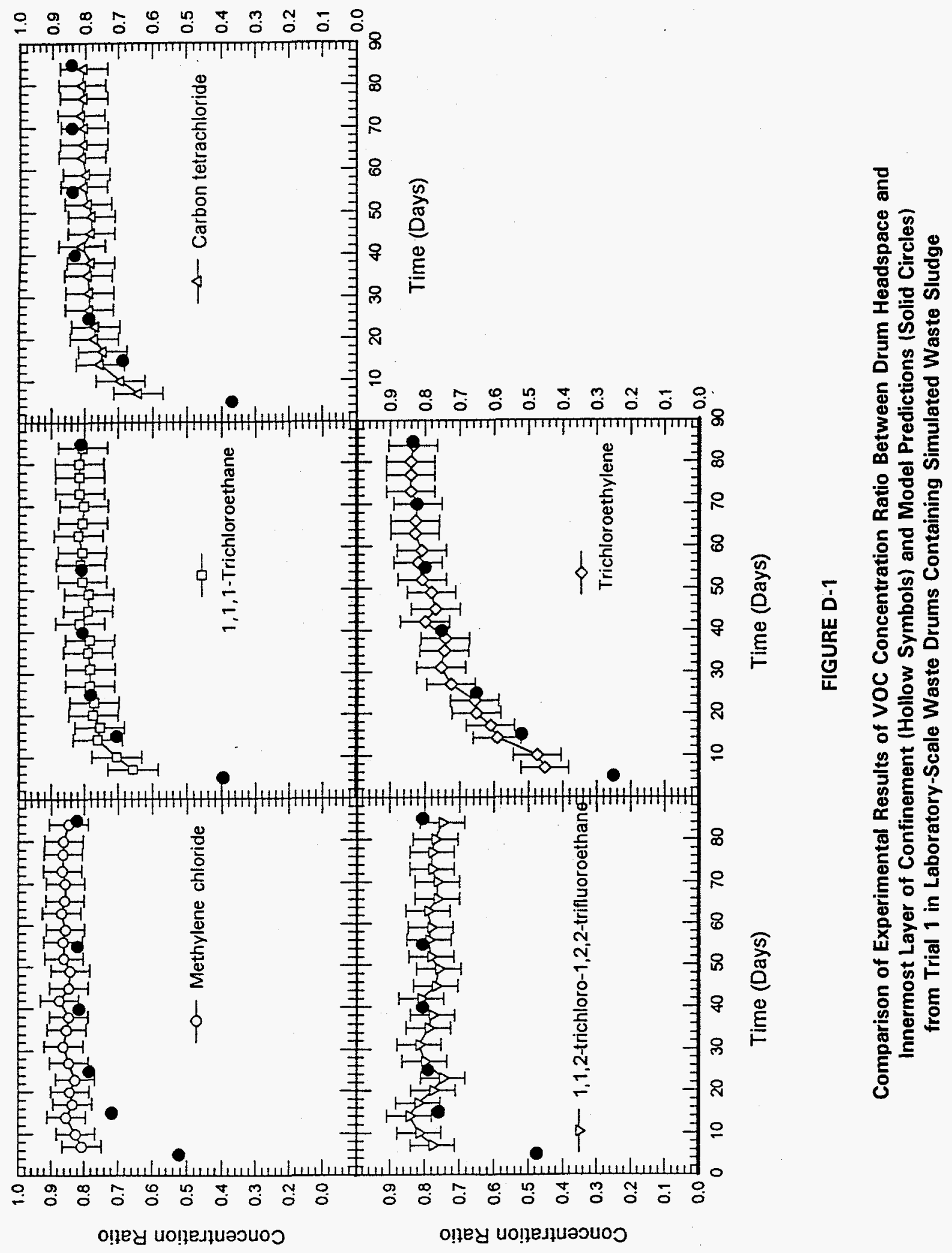




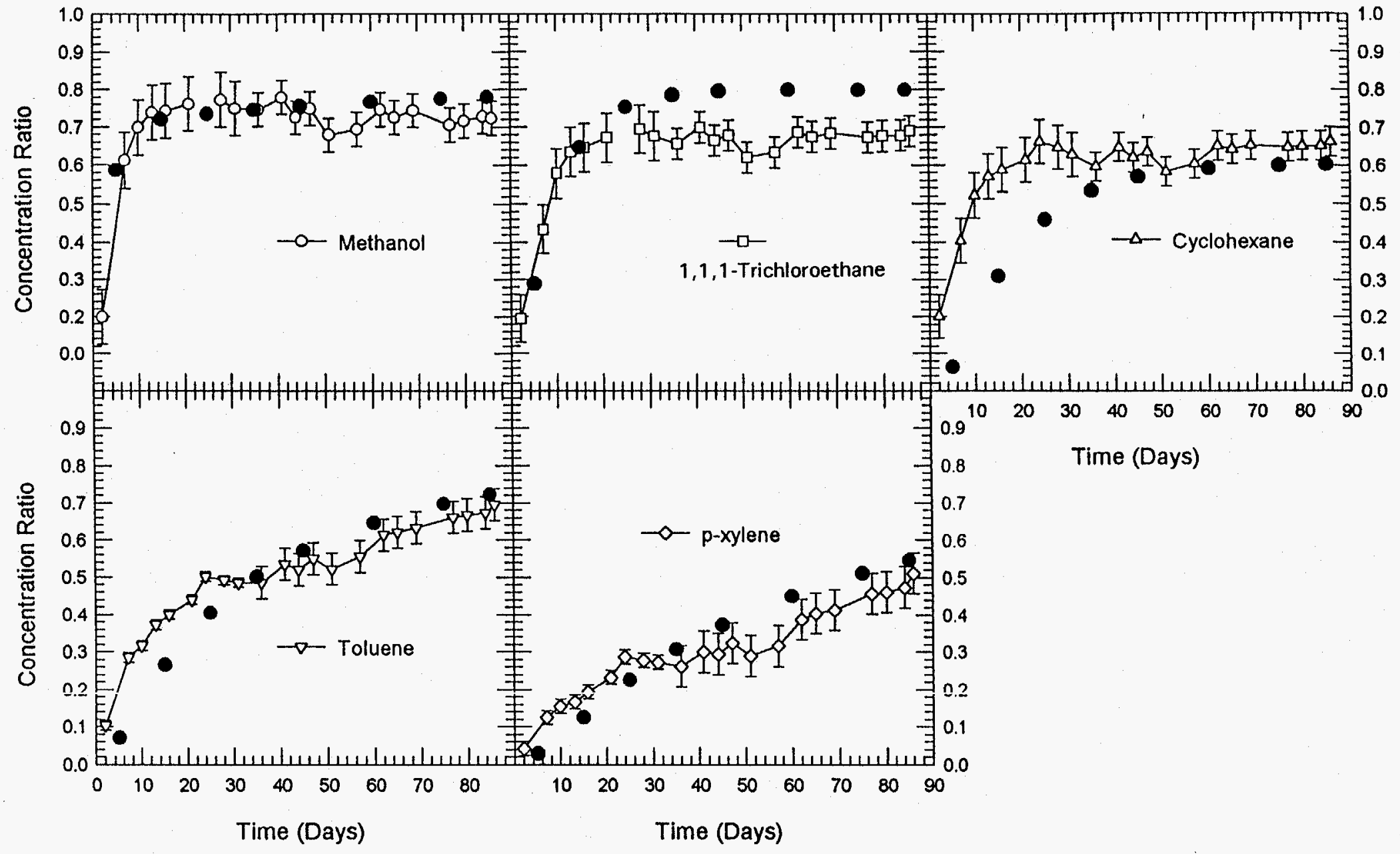

FIGURE D-2

Comparison of Experimental Results of VOC Concentration Ratio Between Drum Headspace and Innermost Layer of Confinement (Hollow Symbols) and Model Predictions (Solid Circles) from Trial 2 in Laboratory-Scale Waste Drums Containing Simulated Waste Sludge 
of the VOC concentration within the innermost layer is not necessary. The assumption of constant VOC concentration simplifies program calculations.

The same computer program used to estimate concentration ratios in a laboratory-scale waste drum was used to estimate the time required to achieve near steady-state conditions in newly packaged waste drums. The program was also adapted to estimate the total vent time required for existing unvented waste drums to achieve near-equilibrium conditions and for existing vented waste drums to reach near steady-state conditions. It was assumed that the primary mechanism for VOC transport across polymer bags is permeation and across the opening in the drum liner lid and drum filter vent is diffusion. All vented drums were assumed to have a NFT-020 drum filter vent. The solubilization of VOCs is only considered in the drum liner because of its relatively large polymer mass. The initial concentration within the innermost layer of confinement is nonzero and remains constant. The VOC concentration throughout each void volume is uniform at all times and is zero outside the waste drum. Multiple layers of bags were treated as a single polymer layer of confinement with a thickness equal to the sum of the individual layers (Liekhus 1995$)$. The temperature was $25^{\circ} \mathrm{C}\left(77^{\circ} \mathrm{F}\right)$ and the pressure was $1 \mathrm{~atm}(76.0 \mathrm{~cm} \mathrm{Hg})$. All vOC properties and other model parameters remain constant. A summary of model parameters used in all three cases of waste drums are summarized in Table D-1. In cases where VOC-specific properties (such as diffusivity, drum filter vent diffusion characteristic, permeability in polyethylene bags, and solubility in drum liner) were not measured, properties were estimated (Liekhus 1994a). The diffusion characteristic of hydrogen and some VOCs across NFT-020 filter vents have been measured (Liekhus 1994). Two methods to estimate VOC equilibrium solubility in the drum liner under saturated vapor conditions and VOC permeability in the polyethylene bags were used in the absence of experimental data. One method was used for the majority of VOCs (Liekhus 1994a). The Brokaw polar correction method was used for methanol and n-butanol (Brodkey and Hershey 1988). The volume fraction of amorphous polymer was determined empirically based on available experimental data for 9 VOCs. The VOC equilibrium concentration was estimated by multiplying the estimated solubility in the drum liner and saturated vapor pressure. The mass transfer coefficient for 9 VOCs was determined by experiment. The mass transfer coefficient for all other VOCs, $\mathrm{k}_{\mathrm{voc}}$, was estimated based on the measured values

$$
\log _{10} k_{v O C}=\frac{\sum_{i=1}^{9} \log _{10} k_{i}}{9}
$$

where $k_{i}$ is the measured mass transfer coefficient of the $i^{\text {th }}$ VOC.

Knowledge of the void volume inside the innermost layer of confinement was not needed since the VOC concentration was assumed to remain constant. The void volume within the large poly bag containing smaller waste packages was assumed to be $20 \mathrm{~L}$. Most of the volume in the large bag was assumed to 
TABLE D-1

Model Parameters Used in Drum Vent Time and Age Calculations

\begin{tabular}{lcccc}
\hline Parameter & Small Bags & Large Bags & Drum Liner & Drum Headspace \\
\hline Number of bags & $0^{\mathrm{a} / 3^{\mathrm{b}}}$ & 2 & $\mathrm{NA}$ & $\mathrm{NA}$ \\
Thickness $(\mathrm{cm})$ & $0.013^{\mathrm{d}}$ & $0.028^{\mathrm{d}}$ & $0.229^{\mathrm{d}}$ & $\mathrm{NA}$ \\
Total surface area $\left(\mathrm{cm}^{2}\right)$ & 14,000 & $3,000^{\mathrm{a}}$ & $15,500^{\mathrm{a}}$ & $\mathrm{NA}$ \\
& & $14,000^{\mathrm{b}}$ & & $28,000^{\mathrm{e}}$ \\
Void volume $\left(\mathrm{cm}^{3}\right)$ & $\mathrm{NA}$ & 20,000 & 40,000 & $\mathrm{NA}$ \\
Diffusion length $(\mathrm{cm})$ & $\mathrm{NA}$ & $\mathrm{NA}$ & $1.2^{\mathrm{d}}$ & $\mathrm{NA}$ \\
Diffusion area $\left(\mathrm{cm}^{2}\right)$ & $\mathrm{NA}$ & $\mathrm{NA}$ & $0.71^{\mathrm{d}}$ & \\
\hline
\end{tabular}

awaste drums containing total of two layers of polymer bags

Waste drums containing total of five layers of polymer bags

"Not applicable

dFrom Liekhus (1995):

${ }^{\ominus}$ From Kudera et al. (1986) 
be occupied by smaller waste packages. The void volume inside the drum liner was assumed to be $\mathbf{4 0}$ L based on the approximate Type II drum liner volume (Kudera et al. 1986) of $186 \mathrm{~L}$ and a median packing efficiency of 80 percent noted in a sample of waste drums (Clements and Kudera 1985). The void volume of the drum headspace was estimated to be $28 \mathrm{~L}$ based on the drum liner volume and the empty drum volume of $217 \mathrm{~L}$ (Kudera et al. 1986).

The total surface area of the large polymer bags in sludge waste drums was assumed to be $3,000 \mathrm{~cm}^{2}$ which is the approximate cross-sectional area of the drum liner. Because of the nature of the sludge waste, it was assumed that the rest of the large bag was sandwiched between the sludge and the liner wall. This was assumed not to be the case in waste drums containing solid waste. In order to estimate the large bag surface area, the bag was assumed to be a cylinder that fills 80 -percent of the drum liner. The total surface area excludes the base of the bag and was estimated to be $14,000 \mathrm{~cm}^{2}$. The total surface from all the small bags was assumed to be at least as great as for the large bag. In reality, the total surface of the small bags is often greater than the large bag surface area (Liekhus 19.5 ).

The drum vent time for newly packaged vented waste drums is when the VOC concentration ratio between the drum headspace and innermost layer of confinement is 90 -percent of the steady-state value. Steadystate conditions were defined as when the calculated VOC concentration in the headspace of the outermost layer of confinement changed less than 0.0001 percent in one day. This criterion was selected since the VOC concentration in the outermost layer of confinement would be the most transient. The primary model assumptions were that the VOC concentration within all layers of confinement are zero except the innermost layer of confinement which is nonzero and constant, the initial VOC concentrations in all small waste packages are identical, and the initial VOC concentration in the polyethylene drum liner is zero. Calculated drum vent times are listed in Table D-2.

In the case of existing unvented waste drums, the drum age was when the VOC concentration in the drum liner headspace was 90-percent of the initial VOC concentration in the innermost layer. In an unvented waste drum, no vent is placed in the drum lid nor is an opening placed in the drum liner lid. Primary assumptions are the same as for newly packaged vented waste drum except that there is no VOC transport to the drum headspace. Calculated drum ages are listed in Table D-3.

The drum vent time for existing vented waste drums is when the VOC concentration ratio between the drum liner headspace and innermost layer is within 10 percent of the steady-state ratio. The primary assumptions were that the initial VOC concentration within the innermost layer is nonzero and constant, the initial concentration within all layers of confinement except the drum headspace are the same, the initial concentration in the drum headspace is zero, and the initial VOC concentration in the drum liner is at its equilibrium value. As a result of this last assumption, VOC solubility in the drum liner is neglected. 
TABLE D-2

Calculated Drum Vent Time (Days) for Newly Packaged Vented Drums

\begin{tabular}{|c|c|c|}
\hline voc & $\begin{array}{c}\text { Case } 1 \\
5 \text { poly bags }\end{array}$ & $\begin{array}{c}\text { Case } 2 \\
2 \text { poly bags }\end{array}$ \\
\hline Acetone & 30 & 52 \\
\hline Benzene & 35 & 57 \\
\hline Bromoform & 75 & 87 \\
\hline Butanol & 40 & 65 \\
\hline Carbon tetrachloride & 51 & 92 \\
\hline Chlorobenzene & 68 & 104 \\
\hline Chloroform & 29 & 46 \\
\hline Cyclohexane & 86 & 126 \\
\hline 1,1-Dichloroethane & 29 & 49 \\
\hline 1,2-Dichloroethane & 33 & 50 \\
\hline 1,1-Dichloroethylene & 32 & 57 \\
\hline cis-1,2-Dichloroethylene & 27 & 42 \\
\hline Ethyl benzene & 92 & 160 \\
\hline Ethyl ether & 51 & 91 \\
\hline Methanol & 64 & 115 \\
\hline Methyl ethyl ketone & 39 & 68 \\
\hline Methyl isobutyl ketone & 76 & 140 \\
\hline Methylene chloride & 32 & 50 \\
\hline 1,1,2,2-Tetrachloroethane & 81 & 100 \\
\hline Tetrachloroethylene & 60 & 90 \\
\hline Toluene & 142 & 225 \\
\hline 1,1,2-Trichloro-1,2,2-trifluoroethane & 53 & 97 \\
\hline 1,1,1-Trichloroethane & 43 & 76 \\
\hline Trichloroethylene & 74 & 119 \\
\hline 1,2,4-Trimethylbenzene & 160 & 274 \\
\hline 1,3,5-Trimethylbenzene & 151 & 267 \\
\hline m-xylene & 92 & 160 \\
\hline o-xylene & 95 & 158 \\
\hline p-xylene & 283 & 422 \\
\hline
\end{tabular}


TABLE D-3

Calculated Drum Age (Days) for Existing Unvented Drums

\begin{tabular}{|c|c|c|}
\hline voc & $\begin{array}{c}\text { Case } 1 \\
5 \text { poly bags }\end{array}$ & $\begin{array}{c}\text { Case } 2 \\
2 \text { poly bags }\end{array}$ \\
\hline Acetone & 16 & 41 \\
\hline Benzene & 15 & 39 \\
\hline Bromoform & 8 & 19 \\
\hline Butanol & 17 & 44 \\
\hline Carbon tetrachloride & 26 & 69 \\
\hline Chlorobenzene & 22 & 56 \\
\hline Chloroform & 13 & 31 \\
\hline Cyclohexane & 88 & 217 \\
\hline 1,1-Dichloroethane & 14 & 35 \\
\hline 1,2-Dichloroethane & 12 & 29 \\
\hline 1,1-Dichloroethylene & 19 & 47 \\
\hline cis-1,2-Dichloroethylene & 11 & 27 \\
\hline Ethyl benzene & 45 & 119 \\
\hline Ethyl ether & 40 & 101 \\
\hline Methanol & 37 & 112 \\
\hline Methyl ethyl ketone & 21 & 54 \\
\hline Methyl isobutyl ketone & 47 & 124 \\
\hline Methylene chloride & 15 & 35 \\
\hline 1,1,2,2-Tetrachloroethane & 12 & 29 \\
\hline Tetrachloroethylene & 19 & 48 \\
\hline Toluene & 48 & 127 \\
\hline 1,1,2-Trichloro-1,2,2-trifluoroethane & 37 & 94 \\
\hline 1,1,1-Trichloroethane & 23 & 59 \\
\hline Trichloroethylene & 25 & 67 \\
\hline 1,2,4-Trimethylbenzene & 71 & 191 \\
\hline 1,3,5-Trimethylbenzene & 73 & 199 \\
\hline m-xylene & 45 & 119 \\
\hline o-xylene & 40 & 105 \\
\hline p-xylene & 75 & 199 \\
\hline
\end{tabular}


Upon venting, the concentration of most VOCs in the drum headspace increases rapidly to a maximum value and then decreases to its steady-state value. In these casses, the criterion that the drum headspace be within 10 percent of the steady-state is not applied until the VOC concentration has exceeded the maximum value. Calculated drum vent times for existing vented waste drums are listed in Table D-4.

The computer program used to calculate drum vent times in the lab-scale waste drums, newly packaged vented waste drums, and existing vented waste drums and to calculate drum age for existing unvented waste drums is listed in Attachment DA. Values used for permeabilities across polyethylene bags and equilibrium concentrations in the rigid drum liner are given in Table D-5.

\section{References}

Brodkey R. S. and H. C. Hershey. 1988. Transport Phenomena - A Unified Approach, McGraw-Hill Book Co., New York.

Clements T. L. and D. E. Kudera. 1985. TRU Waste Sampling Program: Volume I - Waste Characterization." EGG-WM-6503, EG\&G Idaho, Idaho Falls, Idaho.

Kudera D. E., B. W. Brown, M. G. Bullock, K. S. Monti, and R. D. Sanders. 1986. Evaluation of the Aspiration Rate of Hydrogen from a Waste Drum." EGG-WM-7228, EG\&G Idaho, Idaho Falls, Idaho.

Liekhus K. J., G. L. Gresham, E. S. Peterson, C. Rae, N. J. Hotz, and M. J. Connolly. 1994a. Modeling Unsteady-State VOC Transport in Simulated Waste Drums. EGG-WM-10823, Rev. 1, EG\&G Idaho, Idaho Falls, Idaho.

Liekhus K. J. 1998. Transport Characteristics Across Drum Filter Vents and Polymer Bags. EGG-WM-11454, EG\&G Idaho, Idaho Falls, Idaho.

Liekhus K. J. 1995. Characterization of Void Volume VOC Concentration in Vented TRU Waste Drums Final report. INEL-94/0252, Revistor. I, Lockheed Idiaho Technologies Company, Idaho Falls, Idaho.

Liekhus K. J., G. L. Gresham, C. Rae, and M. J. Connolly. 1994.b. VOC Transport in Vented Waste Drums Containing Simulated Waste Sludge. EGG-WM-11205, EG\&G Idaho, Idaho Falls, Idaho.

Liekhus, K. J. and E. S. Peterson. 1995. Measurement of VOC Permeability of Polymer Bags and vOC Solubility in Polyethylene Drum Liner. INEL-95/0164, Lockheed Idaho Technologies Company, Idaho Falls, Idaho. 


\section{TABLE D-4}

\section{Calculated Drum Vent Time (Days) for Existing Vented Drums}

\begin{tabular}{|c|c|c|}
\hline VOC & $\begin{array}{c}\text { Case } 1 \\
5 \text { poly bags }\end{array}$ & $\begin{array}{c}\text { Case } 2 \\
2 \text { poly bags }\end{array}$ \\
\hline Acetone & 14 & 18 \\
\hline Benzene & 14 & 17 \\
\hline Bromoform & 13 & 13 \\
\hline Butanol & 14 & 17 \\
\hline Carbon tetrachloride & 16 & 21 \\
\hline Chlorobenzene & 15 & 16 \\
\hline Chloroform & 14 & 17 \\
\hline Cyclohexane & 24 & 101 \\
\hline 1,1-Dichloroethane & 14 & 18 \\
\hline 1,2-Dichloroethane & 13 & 15 \\
\hline 1,1-Dichloroethylene & 16 & 20 \\
\hline cis-1,2-Dichloroethylene & 13 & 16 \\
\hline Ethyl benzene & 17 & 19 \\
\hline Ethyl ether & 19 & 9 \\
\hline Methanol & 11 & 14 \\
\hline Methyl ethyl ketone & 15 & 19 \\
\hline Methyl isobutyl ketone & 18 & 22 \\
\hline Methylene chloride & 13 & 16 \\
\hline 1,1,2,2-Tetrachloroethane & 14 & 14 \\
\hline Tetrachloroethylene & 15 & 16 \\
\hline Toluene & 14 & 15 \\
\hline 1,1,2-Trichloro-1,2,2-trifluoroethane & 24 & 16 \\
\hline 1,1,1-Trichloroethane & 17 & 22 \\
\hline Trichloroethylene & 14 & 15 \\
\hline 1,2,4-Trimethylbenzene & 17 & 20 \\
\hline 1,3,5-Trimethylbenzene & 18 & 21 \\
\hline m-xylene & 17 & 19 \\
\hline o-xylene & 16 & 18 \\
\hline p-xylene & 17 & 18 \\
\hline
\end{tabular}


TABLE D-5

Permeabilities Across Polyethylene Bag and Equilibrlum Concentration in the Rigid Drum Liner Uised in Calculations

\begin{tabular}{|c|c|c|}
\hline Voc & $\begin{array}{l}\text { Permeability } \\
\text { (Ba) }\end{array}$ & $\begin{array}{c}\text { Equilibrium } \\
\text { Concentration } \\
\left(\mathrm{cm}^{3} \mathrm{STP}\right) /\left(\mathrm{cm}^{3}\right)\end{array}$ \\
\hline Acetone & $151^{a}$ & $4.424^{a}$ \\
\hline Benzene & $27^{a}$ & $4.273^{a}$ \\
\hline Bromoform & $4818^{a}$ & $2.866^{a}$ \\
\hline$n-\left.B u t a n o\right|^{b}$ & $296^{a}$ & $0.402^{\mathrm{a}}$ \\
\hline Carbon tetrachloride & $190^{c}$ & $5.288^{c}$ \\
\hline Chlorobenzene & $604^{a}$ & $2.144^{a}$ \\
\hline Chloroform & $260^{a}$ & $5.604^{a}$ \\
\hline Cyclohexane & $15^{\mathrm{C}}$ & $9.209^{c}$ \\
\hline 1,1-Dichloroethane & $196^{\mathrm{a}}$ & $5.754^{\mathrm{a}}$ \\
\hline 1,2-Dichloroethane & $445^{\mathrm{a}}$ & $4.389^{a}$ \\
\hline 1,1-Dichloroethylene & $109^{a}$ & $8.931^{a}$ \\
\hline cis-1,2-Dichloroethylene & $295^{a}$ & $5.874^{a}$ \\
\hline Ethyl benzene & $262^{a}$ & $1.429^{a}$ \\
\hline Ethyl ether & $41^{a}$ & $4.733^{a}$ \\
\hline Methanol & $135^{c}$ & $4.471^{\mathrm{C}}$ \\
\hline Methyl ethyl ketone & $165^{\mathrm{a}}$ & $3.178^{a}$ \\
\hline Methyl isobutyl ketone & $129^{a}$ & $0.546^{\mathrm{a}}$ \\
\hline Methylene chloride & $260^{\circ}$ & $7.321^{\mathrm{C}}$ \\
\hline 1,1,2,2-Tetrachloroethane & $2301^{a}$ & $1.854^{a}$ \\
\hline Tetrachloroethylene & $609^{a}$ & $2.570^{a}$ \\
\hline Toluene & $670^{\circ}$ & $3.219^{c}$ \\
\hline 1,1,2-Trichloro-1,2,2-trifluoroethane & $40^{c}$ & $1.357^{c}$ \\
\hline 1,1,1-Trichloroethane & $140^{c}$ & $3.235^{c}$ \\
\hline Trichloroethylene & $580^{c}$ & $11.186^{c}$ \\
\hline 1,2,4-Trimethylbenzene & $321^{a}$ & $0.706^{a}$ \\
\hline 1,3,5-Trimethylbenzene & $261^{a}$ & $0.760^{a}$ \\
\hline m-xylene & $263^{a}$ & $1.304^{\mathrm{a}}$ \\
\hline o-xylene & $361^{a}$ & $1.299^{a}$ \\
\hline p-xylene & $810^{\circ}$ & $6.503^{c}$ \\
\hline
\end{tabular}

${ }^{a}$ Estimated values

bPolar correction applied

'Measured values 
ATTACHMENT DA

Computer Program for Calculating Drum Vent Times

DA-1 


\section{ATTACHMENT DA}

\section{Computer Program for Calculating Drum Vent Times}

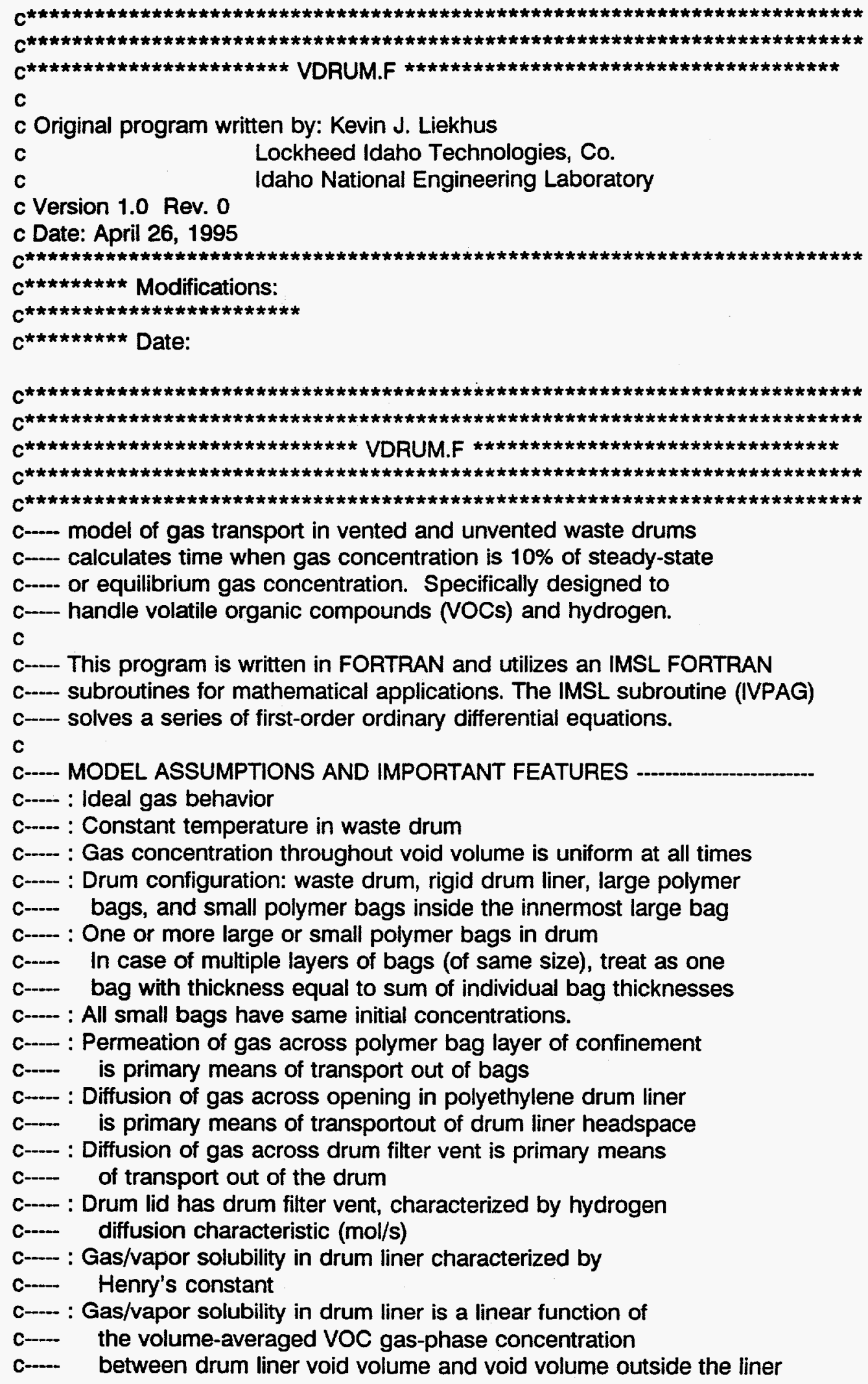


c---- : Dissolved gas concentration in drum liner is uniform at all times

c-- : All model parameter inputs remain constant.

c-- : IMSL methods to solve series of ordinary differential equations

c---- - Gear's backward difference method (chosen in computer program)

c-- - Adams' method

C-...- : Initial conditions

c--- - Gas concentrations within each void volume (specified by user)

c-- - Dissolved gas concentration in drum liner is initially defined

c-... in terms of the initial gas concentration in drum liner headspace

c---- : Boundary conditions

c--.- $\quad$ - VOC concentration outside drum filter vent is zero

c-a- 1) Constant generation rate inside innermost layer (gen $>0$ )

c--- 2) VOC concentration inside innermost layer of confinment

c--. remains constant (gen $=0$ )

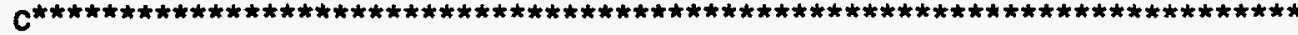

C

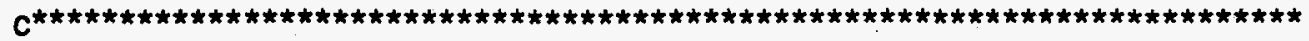

C

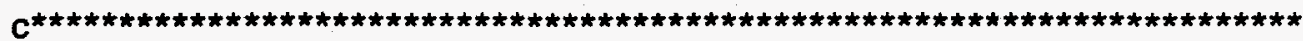

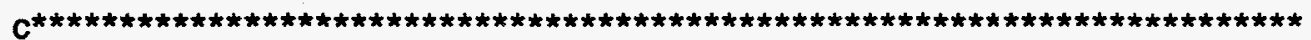

C

character 32 test, ifname, ofname,vocid(35)

real aa(1,1),yy(35,5),yz(5),y(5),k,gen(35)

real pm(35), df(35), amw(35), dv(35),tc(35),pc(35), h(35), ak(35)

real param(50), ap(4), ad(4),v(4),xp(4),xd(4)

integer ivoc(35)

common/qq/p,d,ap,ad,v,xp,xd,pHg, dfh,dvent,c0,tempo,so,k,g

external fen,ivpag,sset

c

c---- User provided input

c---- test - text or title describing contents of input data file

c---- ofname - output file name

c---- nvoc - number of compounds in gas phase of innermost layer

C---- vocid - name of gas or VOC

c---- $y y(i, n)$ - $i$-th VOC concentration (ppmv) in n-th layer of confinement

c--.- $n=1$, headspace within innermost layer of confinement

c---s subsequent layers of confinement are numbered 2, 3, etc.

c--.- amw(i) - gas NOC molecular weight

c---- $\mathrm{pm}(\mathrm{i})$ - gas NOC permeability coefficient in polymer bag,

c-- $\quad \mathrm{cm} 3(\mathrm{STP}) \mathrm{cm} /(\mathrm{cm} 2 \mathrm{~s} \mathrm{~cm} \mathrm{Hg})$

c--.- df(i) - gas NOC diffusivity in air, $\mathrm{cm} 2 / \mathrm{s}$

C---- tc(i) - critical temperature of gas or VOC, $\mathrm{K}$

c---- pc(i) - critical pressure of gas or VOC, atm

C-.-- dv(i) - gas NOC diffusion characteristic across drum filter vent,

c-- $\mathrm{mol} / \mathrm{s}$ (/fraction)

c---- $h(i)$ - gas/NOC Henry's constant for drum liner,

c--- $\quad \mathrm{cm} 3$ polymer atm/cm3 (STP) gas

c--- ak(i) - gas/NOC mass transfer coefficient at drum liner surface, 1/s

c---- gen(i) - 1) $>0$, assume constant gas gen. rate in innermost layer, mol/s

c--- $\quad-2)=0$, assume gas conc. in innermost layer is constant

c--- $\quad-3)=1 . e-6$, gas conc. is not constant, no gas generation

c---- ap(n) - total permeable surface area $(\mathrm{cm} 2)$ of $n$-th layel of confinement

c---- $\operatorname{ad}(n)$ - cross-sectional area of opening (cm2) across $n$-th layer

c---- $v(n)$ - void volume within $n$-th layer of confinement $(\mathrm{cm} 3)$

C--- $x p(n)$ - permeable surface thickness $(\mathrm{cm})$ of $n$-th layer 
c-- $x d(n)$ - diffusional path length $(\mathrm{cm})$ across $n$-th layer of confinement

C- - temp - initial drum temperature, $\mathrm{C}$

c- $\mathrm{pHg}$ - atmospheric pressure, $\mathrm{cm} \mathrm{Hg}$

c-.. dfh - drum filter vent hydrogen diffusion characteristic, mol/s

c

C--._- OTHER MODEL VARIABLES

c-m

c--.. ro - gas constant $(82.06 \mathrm{~cm} 3 \mathrm{~atm} / \mathrm{mol} \mathrm{K})$

c---. patm - atmospheric pressure, atm

c-- tempo - initial drum temperature, $\mathrm{K}$

c--- $\mathrm{co}$ - initial ideal gas concentration in drum, $\mathrm{mol} / \mathrm{cm} 3$

c--neq - maximum number of layers of confinement

c-n $n q=n e q+1$

c-n $\pi$ - steady-state concentration, ppm

c-- $y z(n)-V O C$ concentration in n-th layer of confinement, $\mathrm{mol} / \mathrm{cm} 3$

c-- yz(neq+1) - VOC concentration in drum liner, $\mathrm{cm} 3 \mathrm{VOC} / \mathrm{cm} 3$ polymer

c--- $y(n)-V O C$ concentration in $n$-th layer of confinement, ppm

c--.- $\mathrm{t}$ - time (sec)

c---n nc - number of days simulated in program

c-- yss - VOC concentration in outermost layer of nc-th day

c-.- zneq - VOC concentration in outermost layer on (nc-1)th day

c--.- $\mathrm{p}$ - gas/NOC permeability coefficient in polymer bag,

C-.- $\quad \mathrm{cm} 3$ (STP) $\mathrm{cm} /(\mathrm{cm} 2 \mathrm{~s} \mathrm{~cm} \mathrm{Hg}$ )

c-a d - gas/NOC diffusivity in air, $\mathrm{cm} 2 / \mathrm{s}$

c---- dvent - gas NOC diffusion characteristic across drum filter vent,

c-a $\mathrm{mol} / \mathrm{s}$ (/fraction)

c--- $k$ - gas NOC mass transfer coefficient at drum liner surface, $1 / \mathrm{s}$

c--- g - gas generation rate within innermost layer of confinement, mol/s

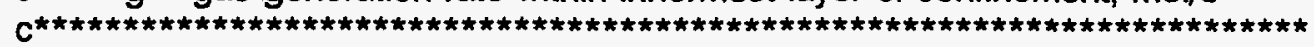

C---- IMSL subroutines and parameters

c-- SSET - IMSL subroutine (sets a vector to a constant value)

c--.- IVPAG - IMSL subroutine (initial-value ODE solver)

C--.- ido - flag indicating state of computation

C---- $\quad a(1,1)$ - matrix used when ODE system is implicit

c--.- tend - value of $t$ at which solution is desired

c---- tol - tolerance for error control

c---- param - vector of length 50 containing optional parameters,

c--- model parameters set to default values

c--- param(4) - maximum number of steps allowed

c-.-. param(10) - switch determining error norm

c--n param(12) - method indicator

c-... 1 = Adams' method;

c---- $\quad 2$ = Gear's backward difference method

C---- FCN - user-supplied subroutine to evaluate functions

C--.- FCNJ - user-supplied subroutine to compute the Jacobian

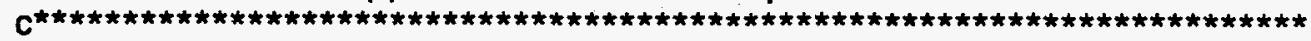

C---- VPROPS - subroutine calculate VOC properties not specified

c---- df - VOC diffusivity in air, $\mathrm{cm} 2 / \mathrm{s}$

c---- dvent - drum filter vent VOC diffusion characteristic, mol/s

c---- so - gas pressure/(total gas concentration*VOC Henry's constant),

c-.- $[(\mathrm{cm} 3 \mathrm{VOC}(\mathrm{STP}) /(\mathrm{cm} 3 \mathrm{polymer})] /(\mathrm{mol} / \mathrm{cm} 3)$

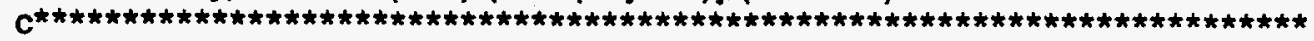

C

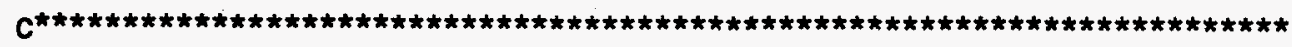

c- 
c recalling input data file name

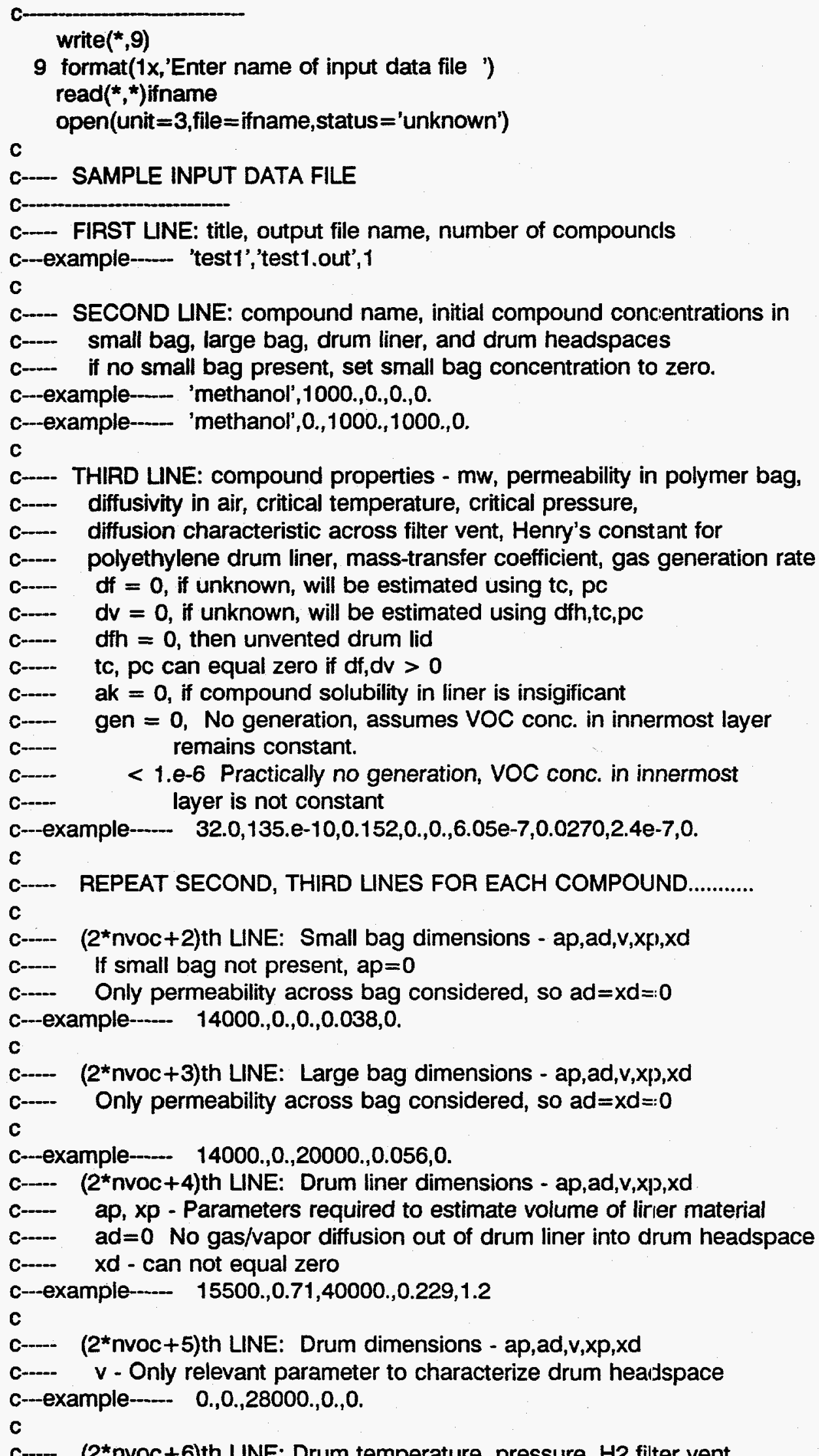

$\left(2^{\star} n v o c+6\right)$ th LINE: Drum temperature, pressure, $\mathrm{H} 2$ filter vent 


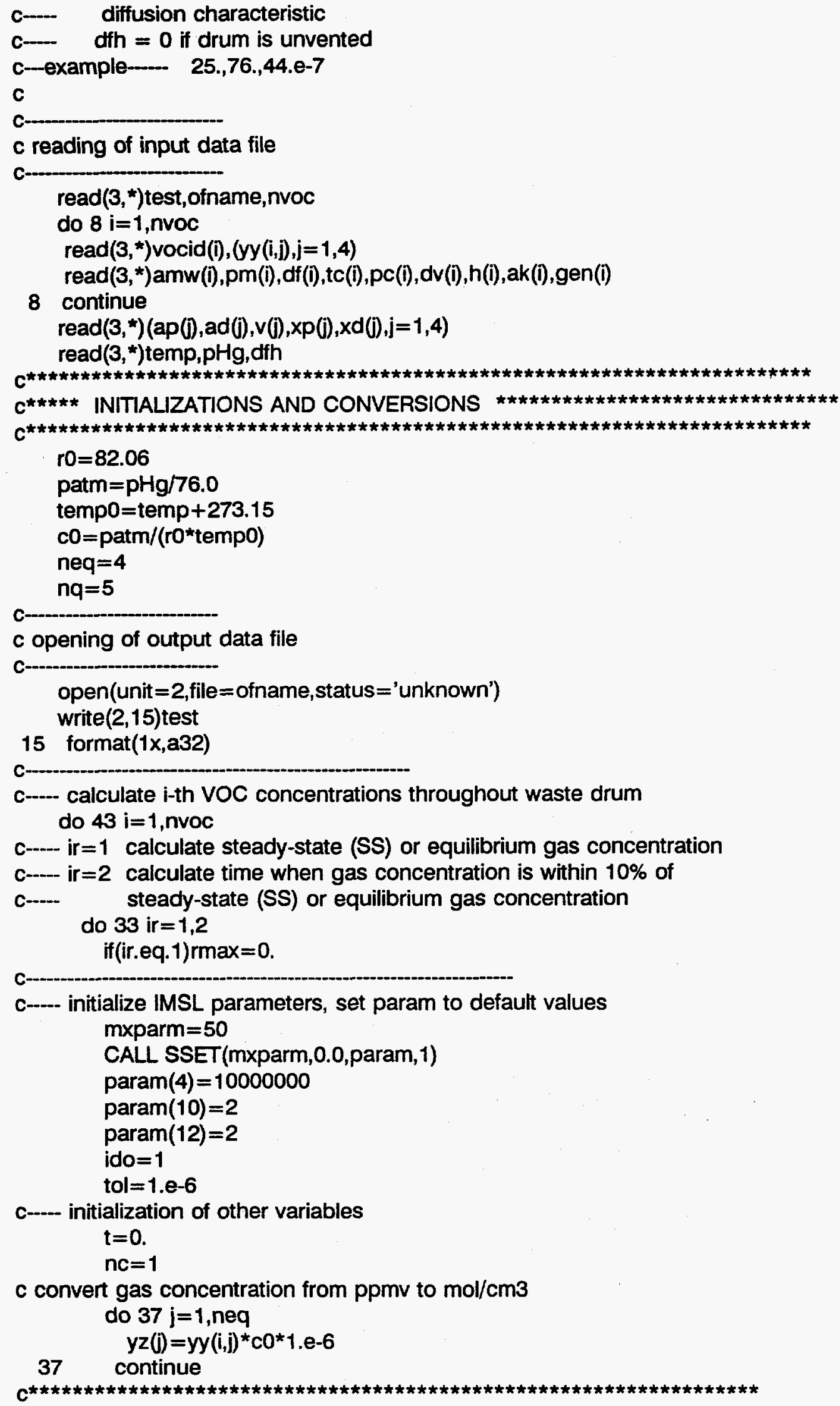

CALL VPROP(amw(i),tc(i),pc(i),pm(i), df(i),c0,dfh,dv(i), 
\#h(i),s0,tempo,patm)

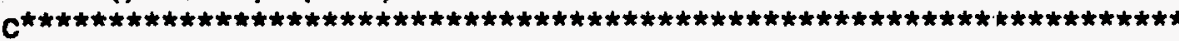

$y z(n q)=y z(3) \star s 0$

$p=p m(i)$

$d=d f(i)$

$d v e n t=d v(i)$

$k=\operatorname{ak}(i)$

$g=g e n(i)$

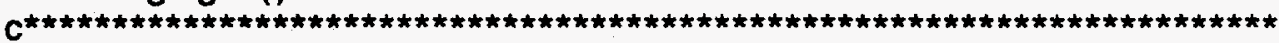

C

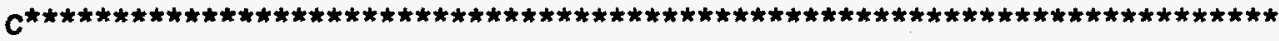

20

if(p.gt.50.e-10)then

$d t=120.50 . e-10 / p$

else

$d t=120.5 \cdot e-10 / p$

end if

tend $=t+d t$

c

CALL IVPAG(ido,nq,fcn,fcnj,aa,t,tend,tol,param,yz)

c

C

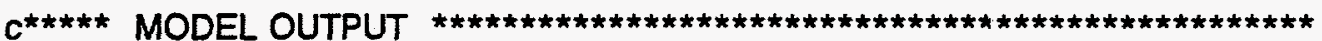

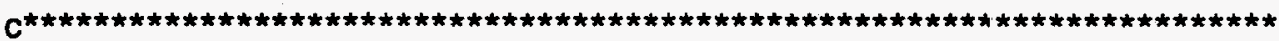

$c-$

c output (every simulated $24 \mathrm{hrs}$ )

c-

if(ifix ((tend +0.1$) / 86400)$.eq.nc) then

do 28 iu $=1$, neq

28

$y(i u)=(y z(i u) / c 0) * 1 . e 6$

continue

yss $=y(4)$

if(ad(3).eq.0.)yss $=y(3)$

sum $=a b s(z n e q-y s s) / y s s$

zneq $=y s s$

if(ir.eq.1)then

c-

c identifying time when max. conc. occurs

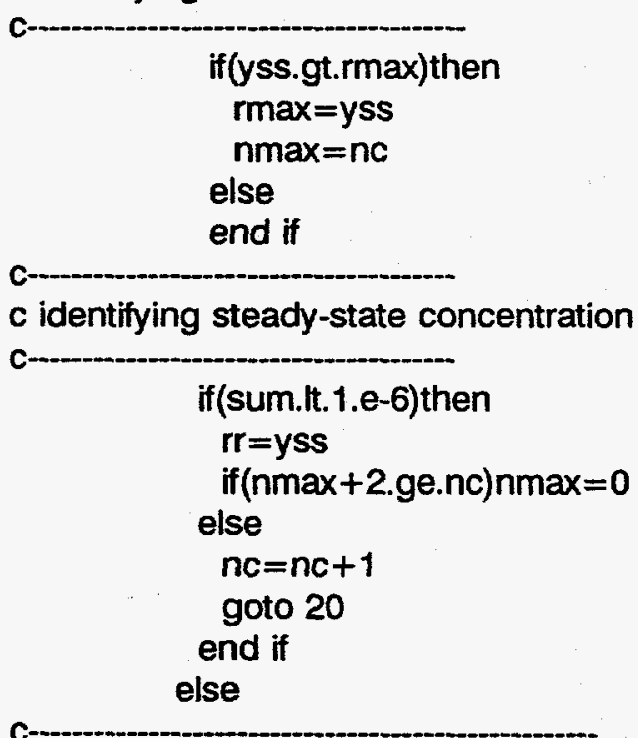


c test if gas concentration is near steady-state (SS)

c or equilibrium concentration (within 10\%)

c

c

c-

c case where SS or equilibrium concentration is asymptoticaly approached

c

$$
\begin{aligned}
& \text { if(nmax.eq.0)then } \\
& \text { if(yss.le.0.9*rr)then }
\end{aligned}
$$$$
\mathrm{nc}=\mathrm{nc}+1
$$$$
\text { goto } 20
$$$$
\text { else }
$$

end if

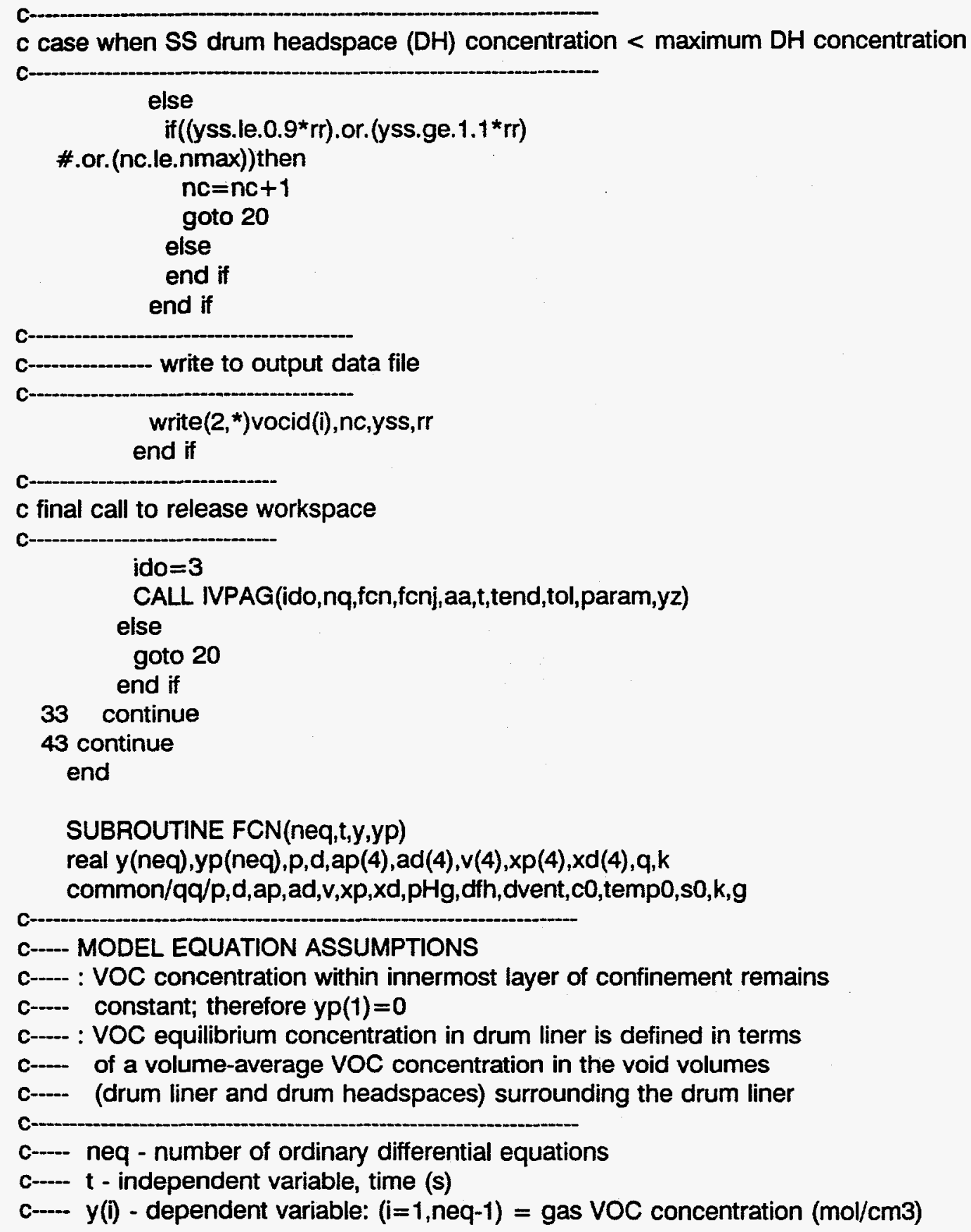


c- $\quad(i=$ neq) VOC concentration in polymer (cm3 VOC/cm3 polymer)

c- yp - first derivative of $y$ with respect to $t$

c--- $a=4.46 e-5^{\star} p^{\star} a p(i)^{\star} \mathrm{pHg} /\left(\times p(i)^{\star} \mathrm{co}\right), \mathrm{cm} 3 / \mathrm{s}$

c-- $p$ - VOC permeability across polyethylene $(\mathrm{cm} 3(\mathrm{STP}) \mathrm{cm} / \mathrm{cm} 2 \mathrm{~s} \mathrm{~cm} \mathrm{Hg}$ )

c-a ap(i) - permeable surface area of $i$-th layer of confinement, $\mathrm{cm} 2$

c-- pHg - system pressure, $\mathrm{cm} \mathrm{Hg}$

c-- $x p(i)$ - boundary thickness of $\mathrm{i}$-th layer of confinement, $\mathrm{cm}$

c--.- $\mathrm{co}$ - ideal gas concentration, $\mathrm{mol} / \mathrm{cm} 3$

$c---b=d^{*} a d(i) / x d(i), c m 3 / s$

c-... d - VOC diffusivity in air, $\mathrm{cm} 2 / \mathrm{s}$

c--.- ad(i) - cross-sectional area of opening in $\mathrm{i}$-th layer of confinement, cm2

c--- $x d(i)$ - diffusional length across opening, $\mathrm{cm}$

c-n $q$ - rate of VOC transport from layer of confinement, mol/s

c--- 94 - fraction of VOC in drum liner headspace of all VOC in both

c---- drum liner and drum headspaces

c---g $\mathrm{g} 5=1-\mathrm{g} 4$

C---- vp - volume of polymer in drum liner, $\mathrm{cm} 3$

c---s - VOC equilibrium concentration in drum liner as defined in terms

c--- of volume-average VOC concentration surrounding drum liner, $\mathrm{cm} 3 \mathrm{VOC} / \mathrm{cm} 3$

c--.- so - VOC equilibrium concentration in drum liner as defined in terms

c--.- of VOC vapor pressure in saturated vapor, $\mathrm{cm} 3 \mathrm{VOC} / \mathrm{cm} 3$

c---- stp - gas concentration $(\mathrm{mol} / \mathrm{cm} 3)$ at standard temperature $(273.15 \mathrm{~K})$

c-- and pressure $(1 \mathrm{~atm})=1 . /\left(82.06^{\star} 273.15\right)=4.461 \mathrm{e}-5 \mathrm{~mol} / \mathrm{cm} 3$

c---- dvent - VOC diffusion characteristic, mol/s

c--.- k - VOC mass-transfer coefficient, $1 / \mathrm{s}$

c--.- small polymer bag

c-

if(ap(1).ne.0.)then

$a=4.46 e-5^{\star} p^{\star} a p(1)^{\star} p H g /\left(x p(1)^{*} c 0\right)$

if(g.eq.0.)then $y p(1)=0$.

$$
\text { else }
$$

$$
\begin{aligned}
& y p(1)=\left(g+a^{\star}(y(2)-y(1))\right) / v(1) \\
& \text { end if }
\end{aligned}
$$

$q=a^{*}(y(2)-y(1))$

else

end if

\section{c}

c---- large poly bag

c-

$a=4.46 e-5^{\star} p^{\star} a p(2)^{\star} p H g /\left(x p(2)^{\star} c 0\right)$

if(ap(1).eq.0.)then

if(g.eq.0.)then

$y p(2)=0$.

else

$y p(2)=\left(g+a^{*}(y(3)-y(2))\right) / v(2)$

end if

else

$y p(2)=\left(-q+a^{*}(y(3)-y(2))\right) / v(2)$

end if

$q=a^{\star}(y(3)-y(2))$

c-

c-.-.- drum liner headspace 


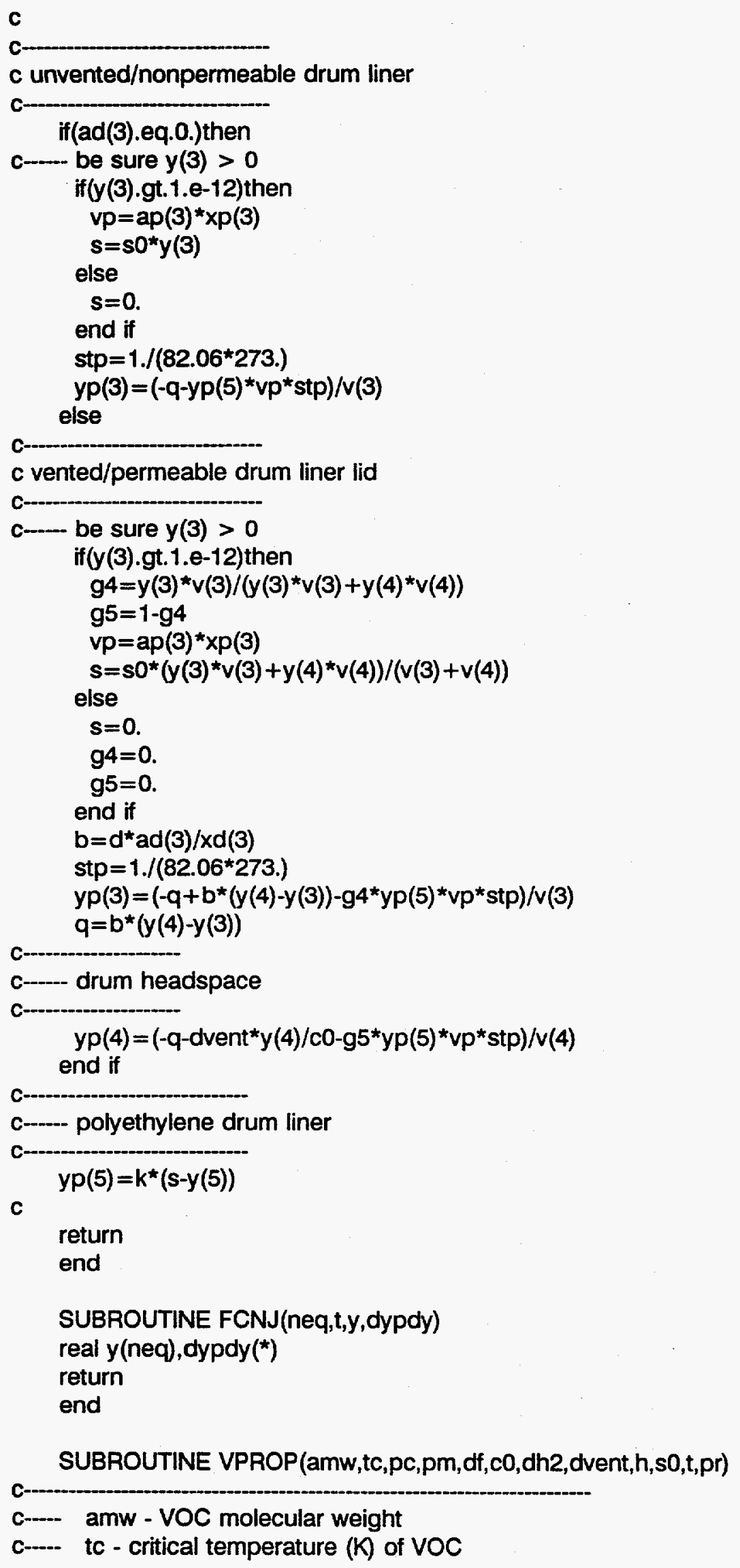


pc - critical pressure (atm) of VOC

C-1.-

C--

pm - VOC permeability across polyethylene at $25 \mathrm{C}$, $\mathrm{cm} 3$ (STP) $\mathrm{cm} / \mathrm{cm} 2 \mathrm{~s} \mathrm{~cm} \mathrm{Hg}$

c-- df - VOC diffusivity in air (at $25 \mathrm{C}$ if temperature not specified)

c-a dvent - drum filter vent VOC diffusion characteristic, mol/s

c--. h - VOC Henry's constant, cm-3 VOC (STP) cm3 polymer (atm)

c-- so - gas pressure/(VOC Henry's constant * total gas concentration)

c-- (cm3 VOC/cm3 poly) (cm3 gas/mol VOC)

c---- pch - critical pressure (atm) of hydrogen

$c-\ldots$ tch - critical temperature $(K)$ of hydrogen

c---- pca - critical pressure (atm) of air

c---- tca - critical temperature $(K)$ of air

c--- h2mw - molecular weight of hydrogen

c--- airmw - molecular weight of air

c-s smw $=1 /$ airmw $+1 / \mathrm{h} 2 \mathrm{mw}=0.5305$

c--- c1 - constant $=2.745 e-4^{*}\left(t^{\star \star} 1.823 / p r\right)$

c

pch $=12.8$

tch $=33.3$

pca $=36.4$

tca $=132$.

$\mathrm{h} 2 \mathrm{mw}=2.016$

airmw $=29$.

$s m w=1$./airmw $+1 / \mathrm{h} 2 \mathrm{mw}$

$c 1=2.745 e-4^{\star}\left(t^{\star \star} 1.823 / p r\right)$

c-

if(df.eq.0.)then

if(tc.ne.0.)then

samw $=$ sqrt(1./airmw+1/amw)

sqmw $=$ samw/sqrt(smw)

df $=c 1^{\star}\left(p c^{\star} p c a\right)^{\star \star}(1 . / 3 .)^{\star}$ samw/sqrt(tca*tc)

else

end if

else

end if

if(dh2.gt.0.)then

if(dvent.eq.0.)then

samw = sqrt(1./airmw+1/amw)

sqmw $=$ samw/sqrt(smw)

dvent $=d h 2^{\star}\left((\mathrm{pc} / \mathrm{pch})^{\star \star}(1 . / 3 .)^{\star}(\mathrm{tc} / \mathrm{tch})^{\star \star}(-0.5)^{\star}\right.$ sqmw $)$

else

end if

else

end if

if(h.ne.0.)then

$\mathrm{s} 0=\mathrm{pr} /\left(\mathrm{CO}{ }^{\star} \mathrm{h}\right)$

else

$s 0=0$.

end if

c

return

end 


\section{APPENDIX E}

Selection of Indicator VOCs 


\section{APPENDIX E}

\section{Selection of Indicator VOCs}

Indicator VOCs were selected by using two separate screening techniques and having the screened VOCs comprise the set of indicator VOCs. The screening techniques are consistent with the purposes for determining gas phase VOC concentrations in drums; one of the screening techniques focused on flammability issues related to operational period drum handling and the second focused on human health risk from inhalation for the operational period. Each screening is described separately below.

\section{Screening for Operational Period Drum Handling}

To screen for operational period drum handling, magnitude of VOC occurrence in headspace gas samples from 465 INEL and RFP drums was examined. VOCs were screened and included as indicator VOCs if the VOC is flammable and the mean detected concentration exceeded 146 ppmv. The value 146 was determined from the lowest lower explosive limit (LEL) of the 19 flammable VOCs, by accounting for the number of flammable VOCs that may be present in a gas mixture (DOE 1995a), and by accounting for the potential innermost bag gas phase VOC concentrations. The lowest LEL of the flammable VOCs is $0.9 \mathrm{v} / \mathrm{v} \%$, or $9,000 \mathrm{ppmv}$. The screening limit is based on the requirement that to be nonflammable, the following must hold for a mixture with 19 flammable VOCs in the innermost bag of a drum:

$$
19 \times 1 B<9,000
$$

where IB is the innermost bag gas phase VOC concentration. The maximum ratio between the predicted inner bag concentration and observed headspace concentration for all VOCs and drums modeled in Liekhus 1995 is 3.24 . Therefore,

$$
H S \times 3.24=I B
$$

where HS is the headspace VOC concentration. Then,

$$
H S<146.2
$$

must hold true and the limit is formulated. The VOCs considered, percent of drums in which the VOC was detected, the mean detected concentration, and the screening results are given in Table E-1. 
TABLE E-1

Screening of Flammable VOCs

\begin{tabular}{|c|c|c|}
\hline VOC & $\begin{array}{l}\text { Percent of Drums With } \\
\text { Detectable Concentrations }\end{array}$ & $\begin{array}{l}\text { Mean of Detected } \\
\text { Concentrations } \\
\text { (ppmv) }\end{array}$ \\
\hline Acetone & 28.8 & 80.2 \\
\hline Benzene & 26.0 & 1.48 \\
\hline 1-Butanol ${ }^{\mathrm{a}}$ & 18.1 & 660. \\
\hline Chlorobenzene & 0.215 & 0.340 \\
\hline Cyclohexane & 25.8 & 54.1 \\
\hline 1,1-Dichloroethane & 17.2 & 1.40 \\
\hline 1,2-Dichloroethane & 10.3 & 0.409 \\
\hline 1,1-Dichloroethylene & 20.9 & 21.1 \\
\hline cis-1,2-Dichloroethylene & 2.80 & 0.729 \\
\hline Ethyl benzene & 12.3 & 5.82 \\
\hline Ethyl ether & 0 & - \\
\hline Methanol $^{\mathrm{a}}$ & 32.3 & 429. \\
\hline Methyl ethyl ketone ${ }^{a}$ & 12.7 & 242. \\
\hline Methyl isobutyl ketone $e^{a}$ & 4.95 & 820. \\
\hline Toluene & 83.4 & 37.4 \\
\hline 1,2,4-Trimethylbenzene & 7.10 & 1.39 \\
\hline 1,3,5-Trimethylbenzene & 5.38 & 0.975 \\
\hline o-Xylene & 12.9 & 3.57 \\
\hline p/m-Xylene & 22.2 & 11.1 \\
\hline
\end{tabular}

${ }^{a}$ Screened for inclusion as indicator VOC 
For drum handling, $n$-butanol, methyl ethyl ketone, methyl isobutyl ketone, and methanol were screened for inclusion in the indicator set.

\section{Screening for Operational Perlod Human Health Risk}

The screening for operational period human health risk was conducted using those voCs listed in both Appendix VIII of 40 CFR Part 261 and in the TRU Waste Characterization Quality Assurance Program Plan (DOE 1983). Then, the VOCs were scored based on the concentration-toxicity screening technique presented by EPA (1989) for the inhalation pathway. The scoring was performed using VOC concentrations in the INEL and RFP drum headspace gases weighted by Waste Matrix Code Group (DOE 19956) to reflect DOE complex inventory. This screening is consistent with screening performed for the Draft Waste Isolation Pilot Plant No-Migration Variance Petition (DOE 1996 ).

Chemicals from the initial set of VOCs that are to be analyzed on a site-specific basis (i.e., formaldehyde, hydrazine, and nitrobenzene) were also omitted. The resulting VOCs are

- Benzene

- Bromoform

- Carbon disulfide

- Carbon tetrachloride

- Chlorobenzene

- Chloroform

- 1,1-Dichloroethylene

- cis-1,2-Dichloroethylene

- Isobutanol

- Methyl ethyl ketone

- Methylene chloride

- 1,1,2,2-Tetrachloroethane

- Tetrachloroethylene

- Toluene

- 1,1,2-Trichloroethane

- Trichloroethylene

- Trichlorofluoromethane

- Vinyl chloride

The chemicals listed were screened using the scoring technique outlined in EPA (1989). First, the headspace concentration in ppmv were converted to a concentration in $\mu \mathrm{g} / \mathrm{m}^{3}$ for carcinogens and $\mathrm{mg} / \mathrm{m}^{3}$ for noncarcinogens. Several chemicals did not have sample quantitation limits (SQLS) reported by the laboratories providing the headspace sampling data; for these chemicals (carbon disulfide, 2-ethoxyethanol, isobutanol, 2-nitropropane, 1,1,2-trichloroethane, trichlorofluoromethane, and vinyl chloride), SQLs were calculated (DOE 19950 ) and one-half the calculated SQL (rounded to two decimal places) was used for the headspace concentration in the scoring process. 
A risk factor was calculated for each $\mathrm{VOC}$ from the weighted average headspace concentration and the toxicity value. The risk factors for all VOCs were summed to yield a total risk factor. The contribution of each VOC to this risk factor was then calculated by dividing the individual risk factor by the total risk factor. The chemicals responsible for approximately 99 percent of the total risk factor were selected as potential indicator VOCs.

The conversion of headspace VOC concentration in ppmv to $\mu \mathrm{g} / \mathrm{m}^{3}$ (for carcinogens) was performed using the following equation:

$$
H S_{c}=(H S)\left(10^{-6} \text { mole fraction/ ppmv }\right)\left(\frac{P \times M V V}{R \times T}\right)\left(10^{6} \mu g / g\right)\left(10^{3} \mathrm{~L} / \mathrm{m}^{3}\right)
$$

where

$$
\begin{array}{ll}
H S_{c} & =\text { weighted average headspace concentration for carcinogens, } \mu \mathrm{g} / \mathrm{m}^{3} \\
P & =\text { pressure, } 1 \text { atm } \\
M W & =\text { molecular weight, } \mathrm{g} / \text { mole } \\
R & =\text { ideal gas constant, } 0.082057 \mathrm{~L} \text { atm/mole } \mathrm{K} \\
T & =\text { temperature, } 298 \mathrm{~K} \\
H S & =\text { weighted average headspace concentration, ppmv }
\end{array}
$$

The conversion of headspace VOC concentration in $\mathrm{ppmv}$ to $\mathrm{mg} / \mathrm{m}^{3}$ (for noncarcinogens) was performed using the following equation:

$$
H S_{n}=(H S)\left(10^{-6} \text { mole traction/ppmv }\right)\left(\frac{P \times M W V}{R \times T}\right)\left(10^{3} \mathrm{mg} / g\right)\left(10^{3} \mathrm{~L} / \mathrm{m}^{3}\right)
$$

where

$$
H S_{n}=\text { weighted average headspace concentration for noncarcinogens, } \mathrm{mg} / \mathrm{m}^{3}
$$

The equation used to calculate the individual risk factors for carcinogens was

$$
R_{d}=H S_{c} \times U R
$$

where

$$
\begin{aligned}
& R_{c i}=\quad \text { risk factor for carcinogenic Voc } i \\
& U R=\quad \text { unit risk factor for VOC } i,\left(\mu \mathrm{g} / \mathrm{m}^{3}\right)^{-1}
\end{aligned}
$$

The equation used to calculate the individual risk factors for noncarcinogens was

$$
R_{n}=\frac{H S_{n}}{R f C}
$$

where

$$
\begin{aligned}
& R_{n i} \\
& R f C=\quad \text { risk factor for noncarcinogenis VOC } i
\end{aligned}
$$


The total risk factor was calculated using the equation

$$
R_{t}=R_{1}+R_{2}+R_{3}+\ldots+R_{l}
$$

where

$$
\begin{array}{lll}
R_{t} & = & \text { total risk factor } \\
R_{1}+\ldots+R_{j}= & \text { risk factors for VOCs } 1 \text { through } i
\end{array}
$$

Separate values of $R_{t}$ were calculated for carcinogens and noncarcinogens. Finally, the ratio of the individual risk to the total risk $\left(R_{c i}\right.$ or $\left.R_{n i} / R_{t}\right)$ was calculated for each chemical. Based on this ratio, the chemicals responsible for approximately 99 percent of the total risk factor were selected as potential indicator VOCs.

Table E-2 presents the VOC screening using the headspace concentrations of the VOCs. The following chemicals were selected as potential indicator VOCs:

- Carcinogens

- Carbon tetrachloride

- Chloroform

- 1,1-Dichloroethylene

- Methylene chloride

- 1,1,2,2-Tetrachloroethane

- Trichloroethylene

- Noncarcinogens

- Carbon disulfide

- Chlorobenzene

- Methyl ethyl ketone

- Toluene

Carbon disulfide was omitted because it is not included as a VOC to be characterized in the headspace gases of waste drums (DOE 1095a). For operational period human health risk, then, 1,1,2,2tetrachloroethane, 1,1-dichloroethylene, carbon tetrachloride, chlorobenzene, chloroform, methylene chloride, methyl ethyl ketone, toluene, and trichloroethylene were included as indicator vOCs.

\section{References}

40 CFR 261. "Identification and Listing of Hazardous Waste", Appendix VIII "Hazardous Constituents." Code of Federal Regulations, Washington, D.C., Office of the Federal Register National Archives and Records Administration.

DOE. 1995a. TRU Waste Characterization Quality Assurance Program Plan. Revision 0, CAO-94-1010, Carlsbad, New Mexico, U.S. Department of Energy.

DOE. 19951:. Waste Isolation Pilot Plant Transuranic Waste Baseline Inventory Report. Revision 1, CAO-94-1005, U.S. Department of Energy, February. 
TABLE E-2

\begin{tabular}{|c|c|c|c|c|c|c|c|c|c|}
\hline Carcinogen & $\begin{array}{c}\text { MW } \\
\text { (g/mole) }\end{array}$ & $\begin{array}{c}\text { Headspace } \\
\text { Conc } \\
\text { (ppmv) }\end{array}$ & & $\begin{array}{l}\text { Headspace } \\
\text { Conc } \\
\left(u g / m^{-3}\right)\end{array}$ & $\begin{array}{c}\text { Chemical } \\
\text { Class }\end{array}$ & $\begin{array}{c}\text { UR } \\
\left(1 / \mathrm{ug} / \mathrm{m}^{*} 3\right)\end{array}$ & $\begin{array}{c}\text { Calculated } \\
\text { Score }\end{array}$ & $\begin{array}{c}\text { Absolute } \\
\text { Score }\end{array}$ & $\begin{array}{l}\text { Percent } \\
\text { of total }\end{array}$ \\
\hline Benzene & 78.11 & 5.73 & $\mathbf{a}$ & $1.83 E+04$ & A & $8.30 E-06 \mathrm{c}$ & 0.15191738 & 0.15191738 & 0.003274378 \\
\hline Bromoform & 252.77 & 5.79 & a & $5.99 E+04$ & B2 & $1.10 \mathrm{E}-06 \mathrm{c}$ & 0.06583622 & 0.06583622 & 0.001419013 \\
\hline Carbon tetrachloride & 153.84 & 408 & a & $2.57 E+06$ & B2 & $1.50 \mathrm{E}-05 \mathrm{c}$ & 38.502488 & 38.502488 & 0.829870235 . \\
\hline Chloraform & 119.39 & 25.21 & $\mathbf{a}$ & $1.23 E+05$ & B2 & $2.30 \mathrm{E}-05 \mathrm{c}$ & 2.83097957 & 2.83097957 & 0.061018023 \\
\hline Methylene chloride & 84.94 & 497.93 & $\mathbf{a}$ & $1.73 E+06$ & $\mathrm{~B} 2$ & 4.70E-07 c & 0.81291757 & 0.81291757 & 0.017521364 \\
\hline 1,1-Dichloroethylene & 96.95 & 7.54 & $\mathbf{a}$ & $2.99 E+04$ & $\mathrm{C}$ & $5.00 E-05 c$ & 1.49471112 & 1.49471112 & $0.032216522 *$ \\
\hline 1,1,2,2-Tetrachloroethane & 167.86 & 5.73 & a & $3.93 E+04$ & C & $5.80 \mathrm{E}-05 \mathrm{c}$ & 2.2813816 & 2.2813816 & 0.049172165 . \\
\hline Tetrachloroethylene & 165.85 & 5.96 & $\mathbf{a}$ & $4.04 E+04$ & C-B2 & $5.80 \mathrm{E}-07 \mathrm{e}$ & 0.02344541 & 0.02344541 & 0.000505335 \\
\hline 1,1,2-Trichloroethane & 133.42 & 0.07 & b & $3.82 E+02$ & C & $1.60 \mathrm{E}-05 \mathrm{c}$ & 0.00611093 & 0.00611093 & 0.000131713 \\
\hline Trichloroethylene & 131.4 & 20.98 & $\mathbf{a}$ & $1.13 E+05$ & $\mathrm{C}-\mathrm{B} 2$ & $1.70 \mathrm{E}-06 \mathrm{e}$ & 0.19165399 & 0.19165399 & 0.004130848 \\
\hline Vinyl chloride & 62.5 & 0.16 & b & $4.09 E+02$ & A & $8.40 E-05 d$ & 0.03435163 & 0.03435163 & 0.000740404 \\
\hline & & & & & & & Total $=$ & 46.3957934 & \\
\hline
\end{tabular}

*Chemicals account for approximately 99 percent of total score

\begin{tabular}{|c|c|c|c|c|c|c|c|c|c|}
\hline Noncarcinogen & $\begin{array}{c}\text { MW } \\
\text { (g/mole) }\end{array}$ & $\begin{array}{c}\text { Headspace } \\
\text { Conc } \\
\text { (ppmv) }\end{array}$ & & $\begin{array}{l}\text { Headspace } \\
\text { Conc } \\
\left(\mathrm{mg} / \mathrm{m}^{`} 3\right)\end{array}$ & $\begin{array}{c}\text { Chemical } \\
\text { Class }\end{array}$ & $\begin{array}{c}\mathrm{RfC} \\
\left(\mathrm{mg} / \mathrm{m}^{\wedge} 3\right)\end{array}$ & $\begin{array}{c}\text { Calculated } \\
\text { Score }\end{array}$ & $\begin{array}{c}\text { Absolute } \\
\text { Score }\end{array}$ & $\begin{array}{l}\text { Percent } \\
\text { of total }\end{array}$ \\
\hline Carbon disulfide & 76.14 & 0.13 & b & 4.05E-01 & No Data & $1.00 \mathrm{E}-02 \mathrm{~d}$ & 40.4784921 & 40.4784921 & $0.018942182 *$ \\
\hline Chlorabenzene & 112.56 & 7.88 & a & $3.63 E+01$ & D & $2.00 E-02 d$ & 1813.62881 & 1813.62881 & 0.848699763 \\
\hline cis-1,2-Dichloroethylene & 96.95 & 5.55 & $\mathbf{a}$ & $2.20 E+01$ & D & & \#DIV/OI & 0 & 0 \\
\hline Isobutanol & 74.12 & 0.13 & b & $3.94 \mathrm{E}-01$ & No Data & & \#DIV/OI & 0 & 0 \\
\hline Methyl ethyl ketone & 72.1 & 42.42 & $\mathbf{a}$ & $1.25 E+02$ & D & $1.00 E+00 c$ & 125.076013 & 125.076013 & 0.058530159 • \\
\hline Toluene & 92.13 & 16.69 & $a$ & $6.29 E+01$ & $D$ & 4.00E-01 c & 157.204697 & 157.204697 & 0.073564992 • \\
\hline Trichlorofluoromethane & 137.38 & 0.07 & b & $3.93 \mathrm{E}-01$ & No Data & $7.00 \mathrm{E}-01 \mathrm{~d}$ & 0.56181278 & 0.56181278 & 0.000262904 \\
\hline & & & & & & & Total $=$ & 2136.94983 & \\
\hline
\end{tabular}

* Chemicals account for approximately 99 percent of total score

a Measured data from INEL and RFP sampling

b $1 / 2$ the calculated samplo quantitation limit c Toxicity data from IRIS (EPA 1994)

d Toxicity data from HEAST (EPA 1994)
eToxicity Data from Superfund Health

Risk Technical Support Center 
DOE. 199sc. Draft Waste Isolation Pilot Plant No-Migration Variance Petition, Phase I Submittal. DOE/CAO-DRAFT-2043, Carlsbad, New Mexico, U.S. Department of Energy, May, in preparation.

EPA. 1989. Risk Assessment Guidance for Superfund, Volume 1, Human Health Evaluation Manual (Part A). EPA/540/1-89/002, Washington, D.C., U.S. Environmental Protection Agency.

EPA. 1994. Health Effects Assessment Summary Tables, FY-94 Annual Update. EPA 540/R-94/020, Washington, D.C., U.S. Environmental Protection Agency, Office of Solid Waste and Emergency Response.

EPA. 1994. Integrated Risk Information System (IRIS). Washington, D.C., U.S. Environmental Protection Agency.

Liekhus, K. J. T9s. Characterization of Void Volume VOC Concentration in Vented TRU Waste Drums. Final Report. INEL-94/0252, Revision 1, Lockheed Idaho Technologies Company, Idaho Falls, Idaho. 
APPENDIX F

Steady-State Model Inputs

F-1 


\section{APPENDIX F}

\section{Model Input for Steady-State Model}

1. Polymer Bags
A. Surface Area
1. Small Bags $=500 \mathrm{~cm}^{2}$ (Liekhus $\$ 995$ )
2. Large bag $=2,550 \mathrm{~cm}^{2}$ (Liekhus 1995 )

B. Layers

1. Small bags

a. Solid waste drums $=3$ layers

b. Sludge drums $=0$ layers

2. Large bags $=2$ layers

C. Bag thickness

1. Small bags $=5 \mathrm{mil}(0.013 \mathrm{~cm})$ (Liekhus 1998$)$

2. Large $\mathrm{bag}=11 \mathrm{mil}(0.028 \mathrm{~cm})$ (Liekhus $\$ 909)$

D. Material $=$ polyethylene (all bags)

2. Drum liner

A. Thickness $=90 \mathrm{mil}(0.229 \mathrm{~cm})$

B. Surface area of lid opening

1. Sludge drums $=5.1 \mathrm{~cm}^{2}$

2. Solid waste drums $=0.71 \mathrm{~cm}^{2}$

C. Diffusion length

1. Sludge drums $=1.4 \mathrm{~cm}$ (Liekhus 1995 )

2. Solid waste drums $=1.2 \mathrm{~cm}$ (Liekhus $\$ 995$ )

3. Drum filter vent $\mathrm{H}_{2}$ diffusion characteristic
A. $42 \times 10^{-7} \mathrm{~mol} \mathrm{~s}^{-1}=$ NFT-20 (Liekhus 1994 )
B. $117 \times 10^{-7} \mathrm{~mol} \mathrm{~s}^{-1}=$ NFT-13 (Liekhus 1994 )

4. VOC-specific parameters

A. Permeability in polyethylene (Table F-1)

1. Measured values (Liekhus 1995 )

2. Estimated values (Liekhus 1995, Appendix C)

B. VOC drum filter vent diffusion characteristic

1. Measured values

2. Estimated values (Liekhus 1999 )

C. VOC diffusivity in air (Liekhus 1995; Liekhus et al. 1994) 
TABLE F-1

Permeabilities Across Polyethylene Bag

\begin{tabular}{|c|c|}
\hline VOC & $\begin{array}{l}\text { Permeability } \\
\text { (Ba) }\end{array}$ \\
\hline Acetone & $151^{a}$ \\
\hline Benzene & $277^{a}$ \\
\hline Bromoform & $4818^{a}$ \\
\hline n-Butanol ${ }^{b}$ & $295.91^{a}$ \\
\hline Carbon tetrachloride & $190^{\circ}$ \\
\hline Chlorobenzene & $604^{a}$ \\
\hline Chloroform & $260^{a}$ \\
\hline Cyclohexane & $15^{c}$ \\
\hline 1,1-Dichloroethane & $196^{\mathrm{a}}$ \\
\hline 1,2-Dichloroethane & $445^{a}$ \\
\hline 1,1-Dichloroethylene & $109^{a}$ \\
\hline cis-1,2-Dichloroethylene & $295^{\mathrm{a}}$ \\
\hline Ethyl benzene & $262^{a}$ \\
\hline Ethyl ether & $41^{a}$ \\
\hline Methanol & $135^{\circ}$ \\
\hline Methyl ethyl ketone & $165^{a}$ \\
\hline Methyl isobutyl ketone & $129^{a}$ \\
\hline Methylene chloride & $260^{\circ}$ \\
\hline 1,1,2,2-Tetrachloroethane & $2301^{a}$ \\
\hline Tetrachloroethylene & $609^{a}$ \\
\hline Toluene & $670^{\circ}$ \\
\hline 1,1,2-Trichloro-1,2,2-trifluoroethane & $40^{\circ}$ \\
\hline 1,1,1-Trichloroethane & $140^{\circ}$ \\
\hline Trichloroethylene & $580^{\circ}$ \\
\hline 1,2,4-Trimethylbenzene & $321^{a}$ \\
\hline 1,3,5-Trimethylbenzene & $261^{a}$ \\
\hline$m$-xylene & $263^{a}$ \\
\hline o-xylene & $361^{a}$ \\
\hline p-xylene & $810^{c}$ \\
\hline
\end{tabular}

EEstimated values

bolar correction applied

"Measured values 


\section{References}

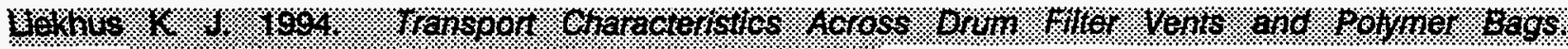

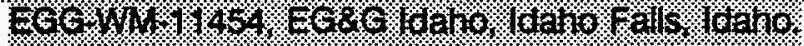

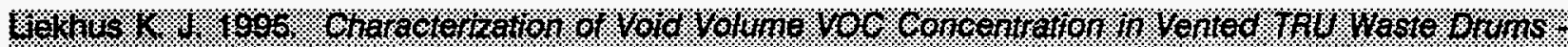

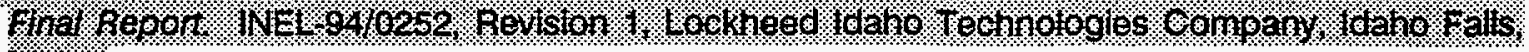
16:410:

Liekhus K. J., G. L. Gresham, C. Rae, and M. J. Connolly. 1994. VOC Transport in Vented Waste Drums Containing Simulated Waste Sludge. EGG-WM-11205, EG\&G Idaho, Idaho Falls, Idaho. 